\title{
Minimalistic In Vitro Culture to Drive Human Naive B Cell Differentiation into Antibody-Secreting Cells
}

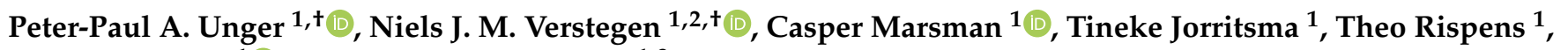 \\ Anja ten Brinke ${ }^{1}\left(\mathbb{D}\right.$ and $S$. Marieke van Ham ${ }^{1,3, *}$ \\ 1 Department of Immunopathology, Sanquin Research and Landsteiner Laboratory, Amsterdam UMC, \\ University of Amsterdam, 1066 CX Amsterdam, The Netherlands; peterpaul.unger@planet.nl (P.-P.A.U.); \\ n.verstegen@sanquin.nl (N.J.M.V.); C.Marsman@sanquin.nl (C.M.); T.Jorritsma@sanquin.nl (T.J.); \\ T.Rispens@sanquin.nl (T.R.); a.tenbrinke@sanquin.nl (A.t.B.) \\ 2 Synthetic Systems Biology and Nuclear Organization, Swammerdam Institute for Life Sciences, \\ University of Amsterdam, 1098 XH Amsterdam, The Netherlands \\ 3 Swammerdam Institute for Life Sciences, University of Amsterdam, 1098 XH Amsterdam, The Netherlands \\ * Correspondence: m.vanham@sanquin.nl; Tel.: +31-(0)20-512-3158 \\ + These authors contributed equally to this work.
}

\section{check for} updates

Citation: Unger, P.-P.A.; Verstegen, N.J.M.; Marsman, C.; Jorritsma, T.; Rispens, T.; ten Brinke, A.; van Ham, S.M. Minimalistic In Vitro Culture to Drive Human Naive B Cell

Differentiation into

Antibody-Secreting Cells. Cells 2021, 10, 1183. https://doi.org/10.3390/ cells10051183

Academic Editors: Juan M. Zapata and Christine Milcarek

Received: 18 February 2021

Accepted: 10 May 2021

Published: 12 May 2021

Publisher's Note: MDPI stays neutral with regard to jurisdictional claims in published maps and institutional affiliations.

Copyright: (c) 2021 by the authors. Licensee MDPI, Basel, Switzerland. This article is an open access article distributed under the terms and conditions of the Creative Commons Attribution (CC BY) license (https:/ / creativecommons.org/licenses/by/ $4.0 /)$.

\begin{abstract}
High-affinity antibody-secreting cells (ASC) arise from terminal differentiation of B-cells after coordinated interactions with $\mathrm{T}$ follicular helper (Tfh) cells in germinal centers (GC). Elucidation of cues promoting human naive B-cells to progress into ASCs is challenging, as this process is notoriously difficult to induce in vitro while maintaining enough cell numbers to investigate the differentiation route(s). Here, we describe a minimalistic in vitro culture system that supports efficient differentiation of human naive B-cells into antibody-secreting cells. Upon initial stimulations, the interplay between level of CD40 costimulation and the Tfh cell-associated cytokines IL-21 and IL-4 determined the magnitude of B-cell expansion, immunoglobulin class-switching and expression of ASC regulator PRDM1. In contrast, the B-cell-specific transcriptional program was maintained, and efficient ASC formation was hampered. Renewed CD40 costimulation and Tfh cytokines exposure induced rapid secondary STAT3 signaling and extensive ASC differentiation, accompanied by repression of B-cell identity factors PAX5, BACH2 and IRF8 and further induction of PRDM1. Our work shows that, like in vivo, renewed CD40L costimulation also induces efficient terminal ASC differentiation after initial B-cell expansion in vitro. This culture system for efficient differentiation of human naive B-cells into ASCs, while also maintaining high cell numbers, may form an important tool in dissecting human naive B-cell differentiation, thereby enabling identification of novel transcriptional regulators and biomarkers for desired and detrimental antibody formation in humans.
\end{abstract}

Keywords: costimulatory molecules; cytokines; cell differentiation; transcription factors

\section{Introduction}

Production of high-affinity antibodies by long-lived plasma cells (PC) and the generation of long-lived memory B-cells (MBC) are essential characteristics of T-cell-dependent humoral immunity to combat invading pathogens and protect upon pathogen re-encounter. On the downside, undesired antibody responses result in pathologies, such as alloimmunity [1,2] and auto-immunity [3-6]. Generation of class-switched high-affinity PCs and MBCs upon antigen encounter of B-cells also requires CD40 costimulation and cytokines, like IL-21 and IL-4, provided by T follicular helper (Tfh) cells in germinal center (GC) reactions in secondary lymphoid organs [7-13]. A GC contains two distinct morphological regions, the dark zone (DZ) and the light zone (LZ). In the DZ, GC B-cells (GCBC) undergo expansion and hypermutation of the genes that encode the immunoglobulin $\mathrm{V}$ region that affect antigen binding. GCBC that acquired B-cell receptor (BCR) mutants with increased 
affinity preferentially bind intact antigen displayed on the surface of follicular dendritic cells (FDC) in the LZ, which results in antigen internalization and presentation of antigenderived peptides via major histocompatibility complex class II molecules (pMHCII) on the B-cell surface [14]. Subsequently, Tfh cells in the LZ engage in cognate interaction with GCBC necessary for GCBC selection. GCBC frequently migrate between DZ/LZ, which ultimately leads to the differentiation of GCBC with the highest affinity into the effector populations [15]. In vivo, GCBC thus repeatedly receive Tfh signals before terminal differentiation into antibody-secreting cells (ASCs), which consist of short-lived plasmablasts (PB) and long-lived PCs.

Insight into the factors that determine the actual fate decision of GCBC to become either MBC or ASC is being gained. Antibody-mediated inhibition and genetically manipulated mouse models have demonstrated an essential requirement for CD40L [16,17] and IL-21 signaling [18,19], but also a contribution of inducible T cell costimulatory (ICOSL) [20], complement receptor (CR) 1 and 2 [21], programmed cell death protein 1 (PD1) and its ligands [22], and CD80 [23] in long-lived PC fate decision have been indicated. CD40 stimulation of naive B-cells combined with cytokines induces efficient proliferation, isotype switching and formation of a CD27 ${ }^{+}$B-cell population in vitro. In contrast, ASC formation is only observed in cultures with very limited B-cell numbers, which do not allow elucidation of the ASC differentiation process $[10,24]$. This demonstrates that the current in vitro culture systems do not reflect the in vivo situation well enough. Previous research has demonstrated that strong CD40 signaling facilitates stable GCBC:Tfh cell interactions to drive the generation of ASC [25]. In addition, graded levels of CD40-CD40L interactions in total B-cells regulated expansion and differentiation in the presence of IL-2, IL-4 and IL-10 in vitro [26]. However, this study did not elucidate the effects of CD40 costimulation on naive B-cell differentiation.

An in vitro system that allows efficient naive B-cell differentiation into the ASCs is highly desired to (i) unravel the process(es) involved in ASC formation, (ii) identify the factors that control the fate decision of differentiating B-cells into ASCs and find targets to modulate antibody formation in vivo and (iii) identify membrane markers associated with the distinct stages of B-cell to ASC formation with diagnostic potential for (early) assessment of undesired short-lived or long-lived antibody formation. Therefore, we established an in vitro culture system for human naive B-cell differentiation into ASCs by varying the level and frequency of CD40 costimulation. We demonstrate that high CD40 costimulation and IL-21 signaling induce naive B-cell expansion but do not allow full ASC formation due to maintenance of B-cell-specific transcription factors, PAX5, IRF8 and $B A C H 2$. Renewed CD40 costimulation and IL-21 allowed effective ASC differentiation by extinguishing the B-cell transcriptional program, which correlated with the re-induction of STAT3 signaling.

\section{Materials and Methods}

\subsection{Cell Lines}

NIH3T3 fibroblast cells (3T3) were stably transfected with Fsp I linearized human CD40L plasmid (a kind gift from G. Freeman) $[27,28]$ and Pvu I linearized pcDNA3neomycin plasmid in 3T3 medium (IMDM (Lonza, Basel, Switzerland) containing 10\% FCS (Bodinco, Alkmaar, the Netherlands), $100 \mathrm{U} / \mathrm{mL}$ penicillin (Invitrogen, Carlsbad, CA, USA), $100 \mu \mathrm{g} / \mathrm{mL}$ streptomycin (Invitrogen, Carlsbad, CA, USA), 2 mM L-glutamine (Invitrogen, Carlsbad, CA, USA) and $50 \mu \mathrm{M} \beta$-mercaptoethanol (Sigma Aldrich, St. Louis, MO, USA) using the Lipofectamine 2000 DNA transfection reagent protocol (Invitrogen, Carlsbad, CA, USA). After three days, transfectants were cultured in 3T3 medium supplemented with $500 \mu \mathrm{g} / \mathrm{mL}$ G418 (Life Technologies, Carlsbad, CA, USA). Transfectants were sorted four times based on their CD40L expression using flow cytometry (anti-CD154; clone TRAP1; BD Bioscience) to select subclones stably expressing low $\left(\mathrm{CD}^{2} \mathrm{~L}^{+}\right)$and intermediate $\left(\mathrm{CD}^{2} \mathrm{~L}^{++}\right)$ CD40L levels than the already available NIH3T3 fibroblasts expressed high (CD40L $\mathrm{L}^{+++}$) human CD40L levels [27]. Comparison of CD40L levels between the 3T3 cells expressing 
low, intermediate and high CD40L levels was done via flow cytometry after trypsinization. These cells were also cultured in 3T3 medium supplemented with $500 \mu \mathrm{g} / \mathrm{mL}$ G418.

\subsection{Isolation of B Cells from Human Healthy Donors}

Buffy coats were collected from voluntary, non-remunerated, adult healthy blood donors (Sanquin Blood Supply, Amsterdam, the Netherlands), who provided written informed consent for the use of remainders of their donation for research as part of routine donor selection and blood collection procedures. Peripheral blood mononucleated cells (PBMCs) were isolated from buffy coats using a Lymphoprep (Axis-Shield PoC AS, Dundee, Scotland) density gradient. Afterward, $\mathrm{CD} 19^{+} \mathrm{B}$-cells were separated using magnetic antiCD19 Dynabeads and DETACHaBEAD (Invitrogen, Carlsbad, CA, USA) according to manufacturer's instructions with purity $>99 \%$.

\subsection{In Vitro Nä̈ve B Cell Differentiation Cultures}

3T3 WT and/or CD40L-expressing 3T3 cells were harvested and irradiated with $30 \mathrm{~Gy}$. Equal numbers $\left(1 \times 10^{4}\right)$ WT or CD40L-expressing $(+,++$ or +++$) 3$ T3 cells or, alternatively, 9:1 WT to CD40L ${ }^{+++}$-expressing 3T3 cell ratio were seeded in B-cell medium (RPMI 1640 (Gibco, Dublin, Ireland) without phenol red containing 5\% FCS, $100 \mathrm{U} / \mathrm{mL}$ penicillin, $100 \mu \mathrm{g} / \mathrm{mL}$ streptomycin, $2 \mathrm{mM}$ L-glutamine, $50 \mu \mathrm{M} \beta$-mercaptoethanol and $20 \mu \mathrm{g} / \mathrm{mL}$ human apotransferrin (Sigma Aldrich, St. Louis, MO, USA; depleted for human IgG with protein $\mathrm{G}$ sepharose)) in 96-well flat-bottom Nunc plates (Thermo Fisher Scientific, Waltham, MA, USA) to allow adherence overnight.

The next day, $\mathrm{CD}_{19^{+} \mathrm{CD} 27^{-} \mathrm{IgG}}{ }^{-}$naive B-cells, to prevent $\mathrm{BCR}$-mediated activation, were sorted on a FACSAria II. To assess proliferation, FACS-sorted naive B-cells were labeled with $0.5 \mu \mathrm{M}$ CFSE (Invitrogen, Carlsbad, CA, USA) in PBS for $15 \mathrm{~min}$ at room temperature. Labeling was stopped by adding B-cell medium. Immediately after labeling, $2.5 \times 10^{4}$ naive B-cells were cultured on the irradiated CD40L-expressing 3T3 fibroblasts in the presence of optimal concentrations (data not shown) of IL-21 (50 ng/mL; Invitrogen, Carlsbad, CA, USA) and/or IL-4 (100 ng/mL; CellGenix, Freiburg im Breisgau, Germany) for six and eleven days, without refreshing medium during these cultures, to assess $\operatorname{IgG}$ B-cell formation, antibody-secreting cell (ASC) differentiation and Ig secretion in the culture supernatants.

For secondary cultures, six-day stimulated B-cells were collected, washed and $2.5 \times 10^{4}$ cells were re-cultured in fresh medium on irradiated CD40L-expressing 3T3 fibroblasts (as described above), including cytokines as in the primary cultures for 5 days.

B-cell receptor stimulations were performed as previously described using soluble anti-IgM antibodies or anti-IgM-coated $3 \mu \mathrm{m}$ polystyrene beads (Spherotech, Lake Forest, IL, USA) [29]. For soluble antibody stimulation, B-cells were first incubated with $10 \mu \mathrm{g} / \mathrm{mL}$ mouse anti-human IgM (clone MH15-1; Sanquin Reagents, Amsterdam, the Netherlands) for $15 \mathrm{~min}$. Excess non-bound antibodies were washed, and conditions were incubated with $10 \mu \mathrm{g} / \mathrm{mL}$ rat anti-mouse IgG1 antibodies for $15 \mathrm{~min}$ to crosslink all bound anti-IgM. Excess non-bound antibodies were washed, and $2.5 \times 10^{4}$ naive B-cells were cultured on irradiated CD40L-expressing 3T3 fibroblasts as described above. For stimulation with anti-IgM-coated beads (coated according to manufacturer's instructions), B-cells were pre-incubated with beads in a B:bead ratio of $1: 2$ for $30 \mathrm{~min}$ at $37^{\circ} \mathrm{C}$ before putting the cells in co-culture with the irradiated CD40L-expressing $3 \mathrm{~T} 3$ fibroblasts as described above.

\subsection{Flow Cytometry}

Cells were first washed with PBS and stained with LIVE/DEAD fixable near-IR (dead cell stain kit, Invitrogen, Carlsbad, CA, USA) for $30 \mathrm{~min}$ at room temperature in the dark. Then, cells were washed with PBS supplemented with $1 \%$ bovine serum albumin. Extracellular staining was performed by incubating the cells for $30 \mathrm{~min}$ at room temperature in the dark with the following antibodies: Anti-CD19 (clone SJ25-C1, BD Bioscience, Franklin Lakes, NJ, USA), anti-CD20 (clone L27, BD Bioscience, Franklin Lakes, 
NJ, USA), anti-CD27 (clone L128, BD Bioscience, Franklin Lakes, NJ, USA; clone O323, eBioscience, San Diego, CA, USA), anti-CD38 (clone HB7, BD Bioscience, Franklin Lakes, NJ, USA) and anti-IgG (clone G18-145, BD Bioscience, Franklin Lakes, NJ, USA or clone MH16-1, Sanquin Reagents, Amsterdam, the Netherlands). Samples were measured on a FACSCanto, FACSLSRII or FACSLSR Fortessa (BD Bioscience, Franklin Lakes, NJ, USA) and analyzed using FlowJo software version 10 (Treestar, Ashland, OR, USA).

\subsection{Analysis of STAT Phosphorylation}

A total of $2 \times 10^{5}$ naive B-cells were cultured with $0.8 \times 10^{5} \mathrm{CD} 4 \mathrm{~L}^{+++}$-expressing $3 \mathrm{~T} 3$ cells in a 24-well Nunc plate (Thermo Fisher Scientific, Waltham, MA, USA) in the absence or presence of IL-21 for 6, 36, 72, 144, 150, 180 and $216 \mathrm{~h}$. IL-21 stimulated Bcells were harvested after $144 \mathrm{~h}$, and secondary cultures were initiated with irradiated

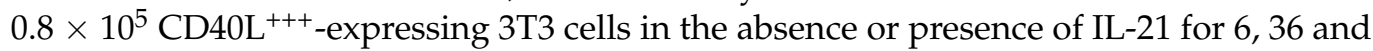
$72 \mathrm{~h}$. Subsequently, the cells were harvested, stained with LIVE/DEAD Fixable Near-IR and anti-CD19 for $15 \mathrm{~min}$ on ice, fixed in 4\% paraformaldehyde (Sigma Aldrich, St. Louis, $\mathrm{MO}, \mathrm{USA}$ ) for $10 \mathrm{~min}$ at $37^{\circ} \mathrm{C}$ and permeabilized with ice-cold methanol (90\%) for $30 \mathrm{~min}$ on ice. The cells were then stained with BD Phosflow anti-pSTAT3 (clone 4/P-STAT3) for $30 \mathrm{~min}$ at room temperature. Samples were measured on FACSLSRII and analyzed using FlowJo software version 10 (Treestar, Ashland, OR, USA).

\subsection{IgM and IgG ELISA of Culture Supernatants}

IgM and IgG levels in supernatants were measured as previously described [30]. In short, plates were coated with monoclonal anti-IgM or anti-IgG $(2 \mu \mathrm{g} / \mathrm{mL}$; clone MH15-1 and MH16-1, respectively; Sanquin Reagents, Amsterdam, the Netherlands) and for detection, horseradish peroxidase-conjugated mouse-anti-human-IgM or mouse-anti-human$\operatorname{IgG}(1 \mu \mathrm{g} / \mathrm{mL}$ in HPE; clone MH15-1 and MH16-1, respectively; Sanquin Reagents, Amsterdam, the Netherlands) were used. The ELISA was developed with $100 \mu \mathrm{g} / \mathrm{mL}$ tetramethylbenzidine in $0.11 \mathrm{~mol} / \mathrm{L}$ sodium acetate $\left(\mathrm{pH}\right.$ 5.5) containing $0.003 \%(v / v) \mathrm{H}_{2} \mathrm{O}_{2}$. The reaction was stopped with $2 \mathrm{M} \mathrm{H}_{2} \mathrm{SO}_{4}$. Absorption at 450 and $540 \mathrm{~nm}$ was measured with a Synergy 2 microplate reader (Biotek, Winooski, VT, USA). Results were related to a titration curve of a serum pool in each plate. The lower-limit detection levels of IgM and IgG ELISA were $5 \mathrm{ng} / \mathrm{mL}$ and $2 \mathrm{ng} / \mathrm{mL}$, respectively.

\subsection{T3 Cell-Specific BCR/Antibody Assay}

3T3 WT cells were harvested, and $2 \times 10^{5} 3 \mathrm{~T} 3$ cells were incubated with culture supernatants that contain secreted antibodies of unswitched $(\operatorname{IgM})$ and class-switched (IgG) isotypes or with $4 \mu \mathrm{g} / \mathrm{mL}$ normal human immunoglobulin (Nanogram $5 \%$; Sanquin Reagents, Amsterdam, the Netherlands) for $30 \mathrm{~min}$ at $4{ }^{\circ} \mathrm{C}$ in the dark. After incubation, cells were washed with PBS supplemented with $1 \%$ bovine serum albumin and subsequently incubated with mouse anti-human IgM (clone MH15-1; Sanquin Reagents, Amsterdam, The Netherlands) and mouse anti-human IgG (clone MH16-1; Sanquin Reagents, Amsterdam, The Netherlands) for $30 \mathrm{~min}$ at $4{ }^{\circ} \mathrm{C}$ in the dark. Samples were measured on a FACSCanto (BD Bioscience, Franklin Lakes, NJ, USA) and analyzed using FlowJo software version 10 (Treestar, Ashland, OR, USA).

\subsection{Wide-Field Microscopy}

WT and human CD40L-expressing 3T3 cells were harvested and irradiated with $30 \mathrm{~Gy}$. $\mathrm{CD} \mathrm{L}^{+++}$-expressing 3T3 cells were labeled with $5.88 \mu \mathrm{M}$ PKH26 (PKH26 Fluorescent Cell Linker Mini Kit for General Cell Membrane Labeling; Sigma Aldrich, St. Louis, MO, USA) in Diluent $C$ for $5 \mathrm{~min}$ at room temperature. Labeling was stopped by adding B-cell medium. Equal numbers $\left(2.1 \times 10^{4}\right) \mathrm{WT}$ or $\mathrm{CD} 4 \mathrm{~L}^{+++}$-expressing $3 \mathrm{~T} 3$ cells or, alternatively, 9:1 WT to CD40L $\mathrm{L}^{+++}$-expressing 3T3 cell ratio were seeded in B-cell medium on Nunc Lab-Tek II Chamber Slide 8 well glass slides (Thermo Fisher Scientific, Waltham, MA, USA) to allow adherence overnight. The next day $5.2 \times 10^{4}$ naive B-cells labeled with $0.5 \mu \mathrm{M}$ 
CFSE (Invitrogen, Carlsbad, CA, USA) were added and imaged every $10 \mathrm{~min}$ for $48 \mathrm{~h}$ on a Zeiss Observer Z1.

\subsection{Real-Time Semi-Quantitative RT-PCR}

Different B-cell subsets (as indicated) were sorted. After sorting, RT-PCR was performed as described before [30]. Primers were developed to span exon-intron junctions and then validated (Table S1). Gene expression levels were measured in duplicate reactions for each sample in StepOnePlus (Applied Biosystems, Foster City, CA, USA) using the SYBR green method (Applied Biosystems, Foster City, CA, USA).

\subsection{Statistical Analysis}

Statistical analysis was performed using Prism 7 (GraphPad, San Diego, CA, USA). The statistical tests used are indicated in figure descriptions. Differences were considered statistically significant when $p \leq 0.05$.

\section{Results}

3.1. The Level of CD40 Costimulation Cooperates with IL-21 and/or IL-4 Signaling to Regulate Human Naive B Cell Expansion and IgG Isotype Switching

The first step in establishing an in vitro human naive B-cell differentiation system was to investigate how variation in CD40 costimulation regulates naive B-cell responses as graded levels of CD40-CD40L interactions regulated expansion and differentiation of total B-cells in vitro [26]. Therefore, 3T3 mouse fibroblasts expressing varying levels of human CD40L were generated (Figure $1 \mathrm{~A}$ ). $\mathrm{CD} 19^{+} \mathrm{CD} 27^{-} \mathrm{IgG}^{-}$human naive B-cells were cultured on WT (=CD40L-negative) or CD40L-expressing cells. The Tfh cell-associated cytokines IL-21 and/or IL-4 were either or not added as it has been shown that in vivo Tfh cells extinguish IL-21 production to switch to IL-4 production, including a transitory IL-21 ${ }^{+} / \mathrm{IL}-$ $4^{+}$double-positive phase that allowed secretion of either one [7]. In line with a previous report [31], the expansion of naive B-cells was highly reliant on costimulation by CD40L (Figure 1B and Figure S1A). Although the proliferation of the naive B-cell population was detected upon CD40 ligation, the number of living cells retrieved 6 days after culture remained low (Figure 1C). This indicates that CD40 ligation is essential for naive B-cell proliferation but that the level of expansion requires additional signals. Indeed, especially in the presence of IL-21, higher CD40 costimulation enhanced B-cell numbers and B-cell proliferation after 6 days in culture (Figure 1B,C and Figure S1B). The addition of IL-4 to the culture system supported CD40-mediated B-cell expansion but provided a threshold for the maximum level of CD40 stimulation that could support B-cell proliferation and live B-cell numbers (Figure 1B,C and Figure S1B). These data indicate that, especially in the presence of IL-21, costimulation via CD40 controls maximal expansion and maintenance of human naive B-cells in an intensity-dependent manner in vitro.

Analysis of effects of the levels of CD40 costimulation on B-cell differentiation showed that the level of CD40 costimulation positively correlated with BCR class switch recombination (CSR) from IgM to IgG in the presence of IL-21 after 6 days of culture (Figure 1B,D). Again, the addition of IL-4 in the system introduced a maximum threshold for the positive effect of CD40 costimulation, although IL-4 did enhance CSR in conditions where low and intermediate levels of CD40L costimulation were provided than IL-21 alone (Figure 1D). Human BCRs did not recognize 3T3 cell antigens (Figure S3), neither did BCR-ligation using soluble anti-IgM antibodies or anti-IgM-coated particles further affect BCR class switching induced by CD40 ligation and IL-21 and/or IL-4 signaling (Figure S2A). Varying levels of CD40 costimulation demonstrated that secretion of IgM and IgG antibodies depended on the strength of costimulation, with the highest level of costimulation being especially supportive for IgM and IgG secretion in the presence of IL-21 (Figure 1E,F). Interestingly, the introduction of IL-4 in the system downmodulated IgM secretion at high CD40 costimulation, but the less affecting secretion of IgG (Figure 1E,F). Correlation between frequency of IgG cells on day 6 and secreted $\operatorname{IgG}$ on day 11 was moderate (Figure S4), indi- 
cating that part, but not all IgG cells after six days of culture, will survive and differentiate between secreting IgG antibodies. These data indicate that in vitro-induced BCR isotype switching from IgM to IgG and immunoglobulin secretion is determined by the level of CD40 costimulation in the presence of a supporting cytokine environment.

As an alternative to our in-house generated cell lines with variable expression of human CD40L, we cultured human naive B-cells on varying numbers of NIH3T3 cells expressing high CD40L levels [27]. Live imaging of these in vitro cultures demonstrated that the number of B-cells that interact with a CD40L-expressing cell significantly increased when only limited CD40L-expressing cells are available (Figure S5A,B). This suggests that in vitro B-cells only generate stable interaction with cells expressing CD40L. Similar to stimulation of naive B-cells with feeder cells expressing variable levels of CD40L per cell, the proliferation of naive B-cells was not affected by a reduced number of CD40L-expressing cells (Figure S6A) but was increased by both cytokines IL-21 and IL-4 (Figure S6B). Confirming the observations using cell lines with different expression levels of CD40L, reducing the number of CD40L-expressing feeder cells also altered the number of viable B-cells after 6 days of culture (Figure 1G,H). In IL-4 conditions, B-cell expansion and maintenance were enhanced when the number of CD40L-expressing feeder cells was reduced 9-fold, whereas, in the presence of IL-21 varying, the number of CD40L-expressing feeders did not affect B-cell expansion and maintenance (Figure 1G,H). BCR isotype switching mainly occurred with highly abundant CD40L-expressing feeder cells in the presence of IL-21 (Figure 1G,I). Like stimulations with feeder cells with low and intermediate expression levels of CD40L, the frequency of BCR isotype switching to IgG cells was increased with the lower number of CD40L-expressing cells in the presence of IL-4. Isotype switching is regulated by activation-induced cytidine deaminase (AICDA) [32]. Expression of AICDA was increased by increasing the number of CD40L-expressing cells in the presence of IL-21 and/or IL-4, with a maximum of $A I C D A$ expression when only IL-21 was present (Figure S6C). While IgM and IgG antibody secretion increased with higher amounts of CD40L-expressing cells and IL-21, IgG antibody-secretion in a micro-environment that included IL-4 showed a maximal beneficial effect of the number of CD40L-expressing cells (Figure 1J,K). This was in line with the observations made when naive B-cells were stimulated with feeder cells exhibiting varying expression levels of CD40L (Figure 1E,F). Altogether these data demonstrate that CD40L expression levels and the number of CD40L-expressing cells both regulate naive B-cell survival, IgG isotype switching, and immunoglobulin secretion.

\subsection{The Level of CD40 Costimulation in Crosstalk with IL-4/IL-21 Signaling Regulates Differentiation of Human Naive B Cells into CD $27^{+} \mathrm{CD} 38^{-}$B Cells and Antibody-Secreting Cells}

To investigate how variation in CD40 costimulation regulates naive B-cell differentiation into $\mathrm{CD} 27^{+} \mathrm{CD} 38^{-}$B-cells, a B-cells phenotype observed in human MBCs in blood and in activated B-cells, and $\mathrm{CD} 27^{+} \mathrm{CD} 38^{+}$antibody-secreting cells (ASCs), human naive B-cells were cultured on 3T3s expressing varying levels of human CD40L for 11 days. Naive B-cell differentiation into $\mathrm{CD} 27^{+} \mathrm{CD} 38^{-}$B-cells was highly induced in conditions that included IL-4 and low CD40 costimulation (Figure 2A,B). Strikingly, increased levels of CD40L costimulation decreased the formation of the $\mathrm{CD} 27^{+} \mathrm{CD} 38^{-} \mathrm{B}$-cell population (Figure 2B). IL-21 repressed differentiation into $\mathrm{CD} 27^{+} \mathrm{CD} 38^{-} \mathrm{B}$-cells in the presence of IL-4 and a low-level of CD40 costimulation (Figure 2A,B). Analysis of CD27 ${ }^{+} \mathrm{CD} 38^{+}$ASC differentiation showed a significant induction, although frequencies were low (to around $3 \%$ ), and only in the presence of IL-21 (Figure 2C). Interestingly, additional B-cell receptor $(B C R)$ triggering did not affect this differentiation process in vitro (Figure S2B,C). 
A

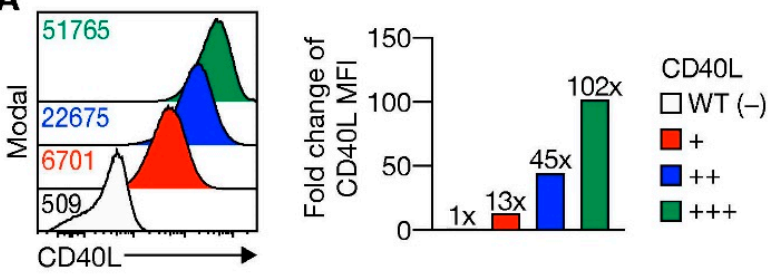

C

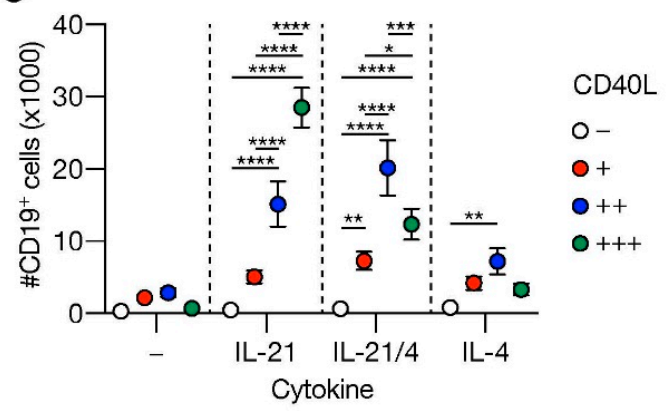

D

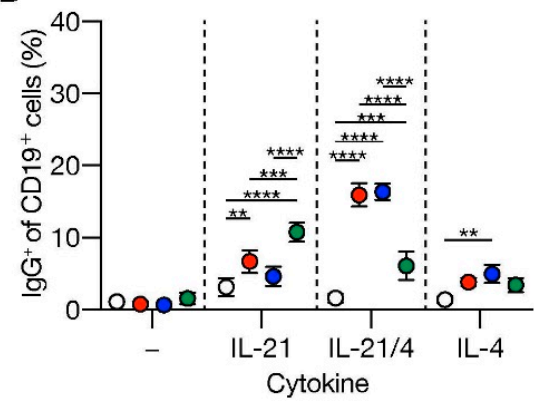

G
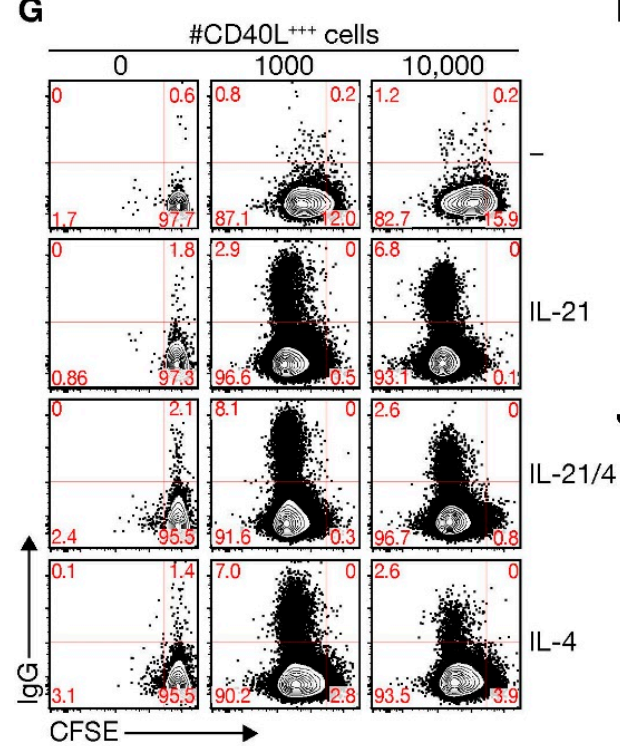

E
B
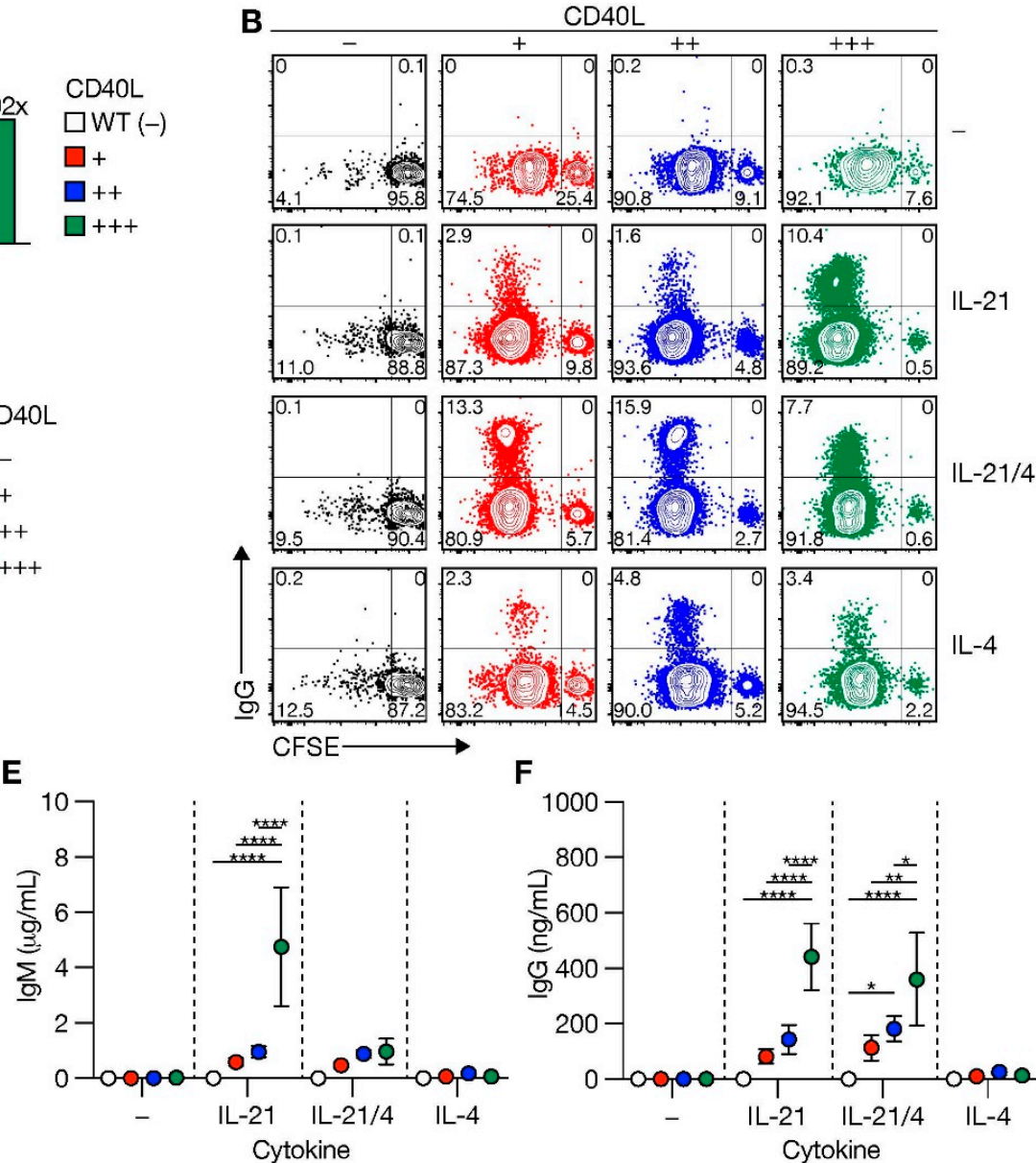

\#CD40L ${ }^{+++}$cells
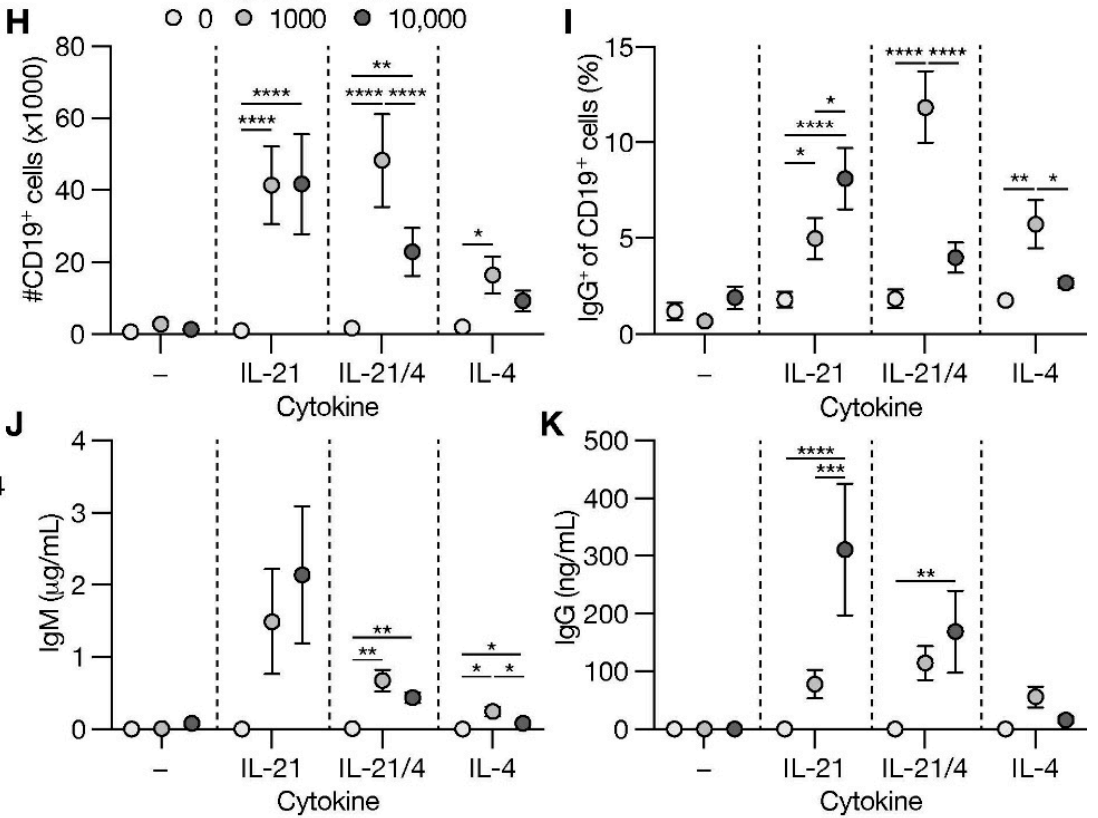

Figure 1. Level of CD40L expression and number of CD40L feeder cells supports human naive B-cell expansion and IgG class switching. (A) Representative histograms (left) of human CD40L expression stably transfected 3T3 fibroblasts expressing various amounts of human CD40L $(+,++$ or +++$)$ compared to non-transfected 3T3 cells (WT; -$)$. Numbers indicate the mean fluorescence intensity (MFI) of CD40L expression. Fold changes compared to WT controls of CD40L MFI are shown in the right panel (data shown represent three separate experiments). (B-D) Human CFSE-labeled naive B-cells 
were cultured on 3T3 cells expressing varying levels of CD40L with or without IL-21 and/or IL-4 for 6 days and analyzed for proliferation and class switching to surface $\operatorname{IgG}\left((\mathbf{B})\right.$; representative plots). The number of live CD19 ${ }^{+}$B-cells $(\mathbf{C})$ and surface IgG-expression (D) was quantified after the cultures by flow cytometry analysis $(n=6)$. (E-F) Cumulative secretion of IgM $((\mathbf{E}) ; n=9)$ and $\operatorname{IgG}((\mathbf{F}) ; n=8)$ measured in culture supernatants after 11 days. $(\mathbf{G})$ Representative plots of CFSE-labeled human naive B-cells cultured on 0/1000/10,000 CD40L $\mathrm{L}^{+++}$-expressing 3T3 cells (supplemented to 10,000 with WT 3T3 cells) with or without IL-21 and/or IL-4 for 6 days. (H-I) Number of live CD19+ events ((C); $n=9)$ and the frequency of IgG ${ }^{+}$

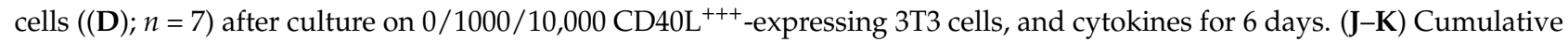
$\operatorname{IgM}((\mathbf{F}) ; n=7)$ and $\operatorname{IgG}((\mathbf{G}) ; n=7)$ levels measured in culture supernatants after 11 days. Data are shown as mean \pm SEM of independent experiments. Single experiments were conducted in triplicate. Data were analyzed by a two-way ANOVA followed by Tukey's multiple comparison test. ${ }^{*} P \leq 0.05,{ }^{* *} P \leq 0.01,{ }^{* * *} P \leq 0.001,{ }^{* * * *} P \leq 0.0001$.

Next, we assessed whether B-cell differentiation was regulated by the amount of CD40L-expressing feeder cells. Interestingly, the number of CD40L-expressing cells attenuated IL-4-dependent induction of CD27 ${ }^{+} \mathrm{CD} 38^{-}$B-cells, which was decreased by IL-21 (Figure 2D,E). Similar to stimulations with feeder cells that exhibit variation in CD40L surface densities, ASC differentiation occurred to a minimal extent ( 0.5-3\%), mainly in the presence of IL-21 with highly abundant CD40L-expressing cells (Figure 2D,F).

These data demonstrate that specifically lower CD40 costimulation in the presence of IL-4 supports naive B-cell differentiation into $\mathrm{CD} 27^{+} \mathrm{CD} 38^{-}$B-cells in vitro, albeit with low numbers of live CD19+ cells. In contrast, higher CD40 costimulation in the presence of IL-21 promotes naive B-cell differentiation into $\mathrm{CD} 27^{+} \mathrm{CD} 38^{+} \mathrm{ASCs}$.

\subsection{High CD40 Costimulation in the Presence of IL-21 Induces PRDM1 (BLIMP1) Expression, but Does Not Extinguish B Cell Lineage Program}

To elucidate why only limited ASC differentiation was induced after 11 days of culture in the presence of highly abundant CD40L and IL-21, expression of transcriptional regulators of the B-cell and ASC fate was assessed at day 9 (Figure 3A). Comparing FACS-sorted differentiated $\left(\mathrm{CD} 27^{+} \mathrm{CD} 38^{-}\right)$and undifferentiated $\left(\mathrm{CD} 27^{-} \mathrm{CD} 38^{-}\right)$cells after 9 days in culture (Figure 3B) showed that CD40L-expressing cells in the presence of IL-21 significantly induced PRDM1 mRNA levels in the differentiated subsets, whereas the addition of IL-4 fully abolished PRDM1 expression (Figure 3C). In contrast, XBP1, critical for the development of ASCs, was highly induced in conditions with IL-4 and limited CD40Lexpressing cells (Figure 3D). Despite significant induction of the ASC regulator PRDM1, the B-cell-specific regulators, PAX5, BACH2 and IRF8, were not significantly changed in the $\mathrm{CD}_{2} 7^{+}$subset compared to $\mathrm{CD}_{2} 7^{-}$subset (Figure $3 \mathrm{E}-\mathrm{G}$ ). These data show that in vitro stimulated naive B-cells that do not show strong ASC formation become transcriptionally primed for ASC differentiation via upregulation of CD40L/IL-21-mediated PRDM1 gene expression but still maintain the B-cell identity program.

\subsection{Secondary Cultures Including CD40L/IL-21 Drive Optimal ASC Differentiation}

Next, we assessed which essential cues were lacking in our minimal in vitro culture system to promote substantial terminal ASC differentiation upon naive B-cell stimulation. In vivo, differentiation of B-cells is dependent on repeated interactions and signals provided by Tfh cells in mature GCs that are formed 5 to 7 days after immunization [15]. To achieve a closer simulation of the in vivo situation, cells were harvested 6 days after starting the primary culture and re-cultured in a secondary culture with CD40L-expressing feeder cells and cytokines (Figure 4A). Remarkably, re-culturing under high CD40 costimulatory conditions in the presence of IL-21 induced prominent and significantly more CD27 ${ }^{+} \mathrm{CD} 38^{+}$ cells than initial culture only (Figure 4B,C). Renewed culture with low CD40 costimulation also induced ASC differentiation in the presence of IL-21 and IL-4 (and significantly increased the number of live CD19+ cells; Figure S7), but not with IL-21 alone. The extensive ASC differentiation after initial expansion resulted in a profound population of ASC (Figure 4D). Remarkably, a more detailed analysis revealed an induction of CD138 ${ }^{+}$ PCs upon renewed costimulation/cytokine culture during naive B-cell differentiation 
(Figure $4 \mathrm{E}, \mathrm{F})$. Moreover, the secretion of $\operatorname{IgM}$ and IgG was profoundly enhanced in the secondary cultures ( 5 days cumulative) than the primary cultures (11 days cumulative) and was mediated by IL-21 (Figure $4 \mathrm{G}, \mathrm{H}$ ). These data demonstrate that renewed culture with CD40L and the cytokines IL-21 and IL-4 are required to finalize the differentiation of human naive B-cells into $\mathrm{CD} 138^{+} \mathrm{PC}$ in vitro.

A

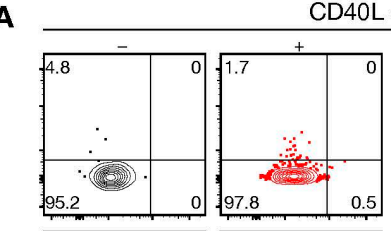

CD40L density
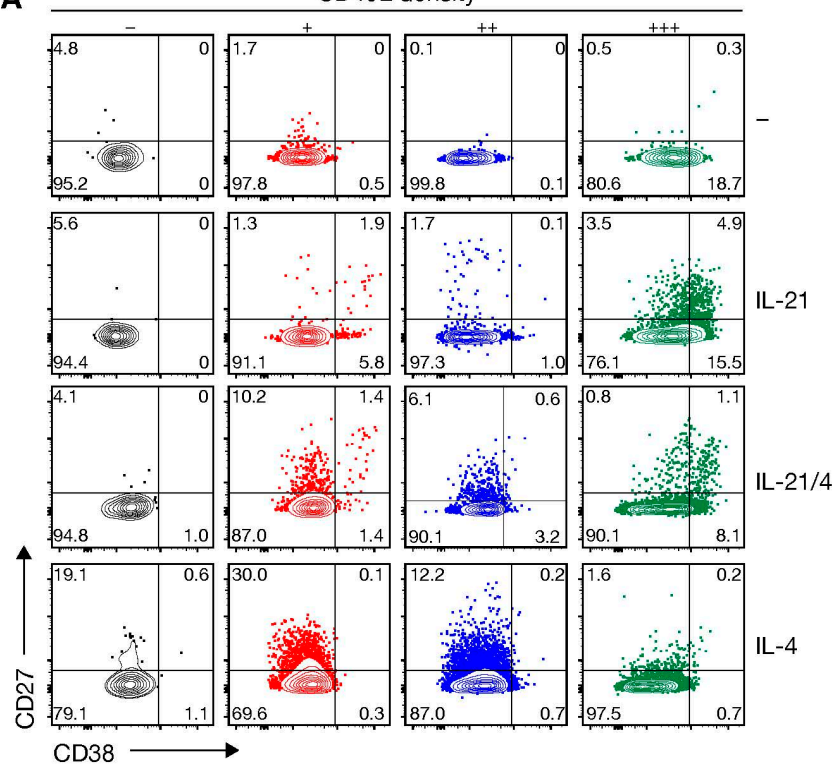

D

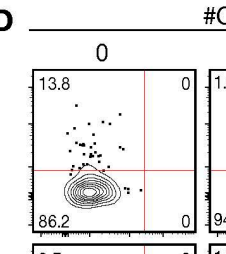

\#CD40L ${ }^{+++}$cells
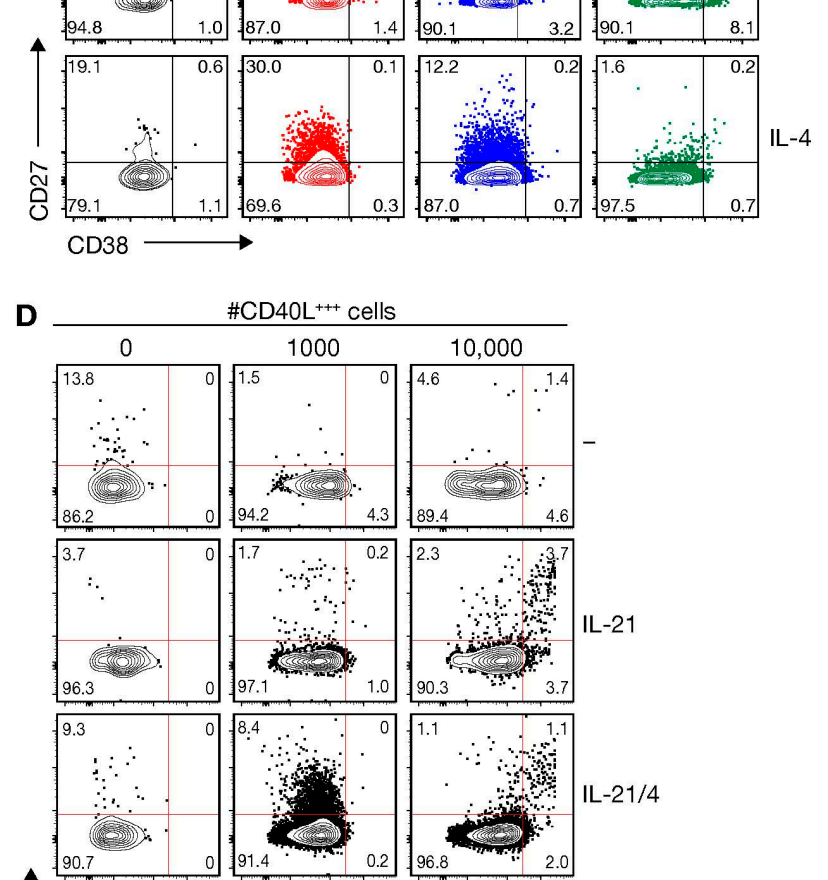

命

CD
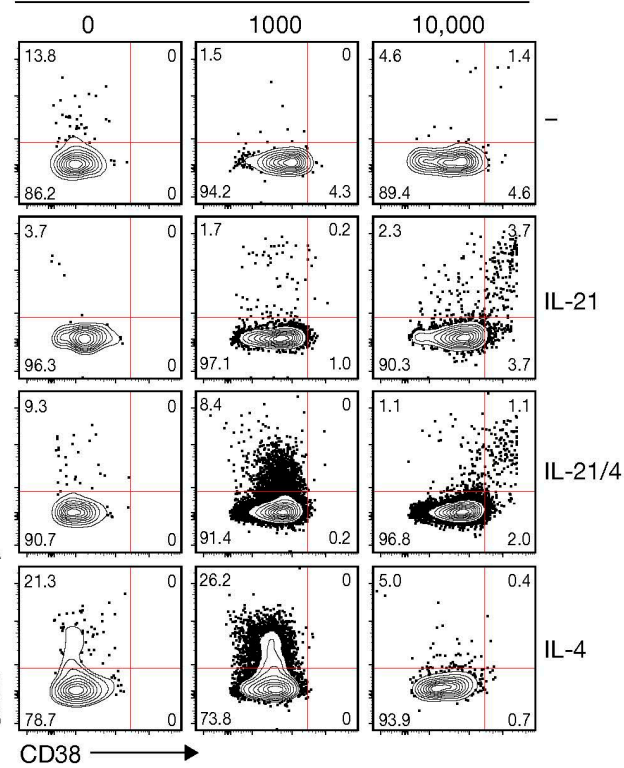

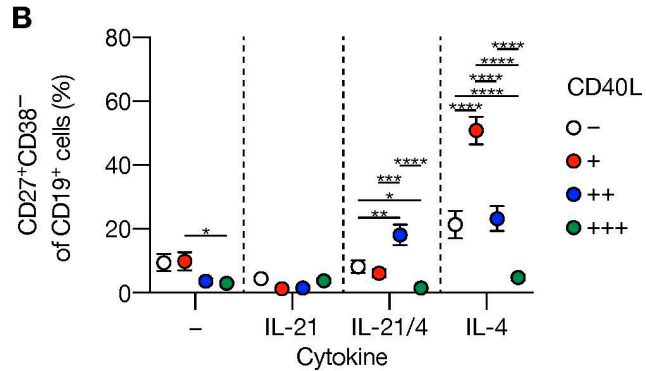

C
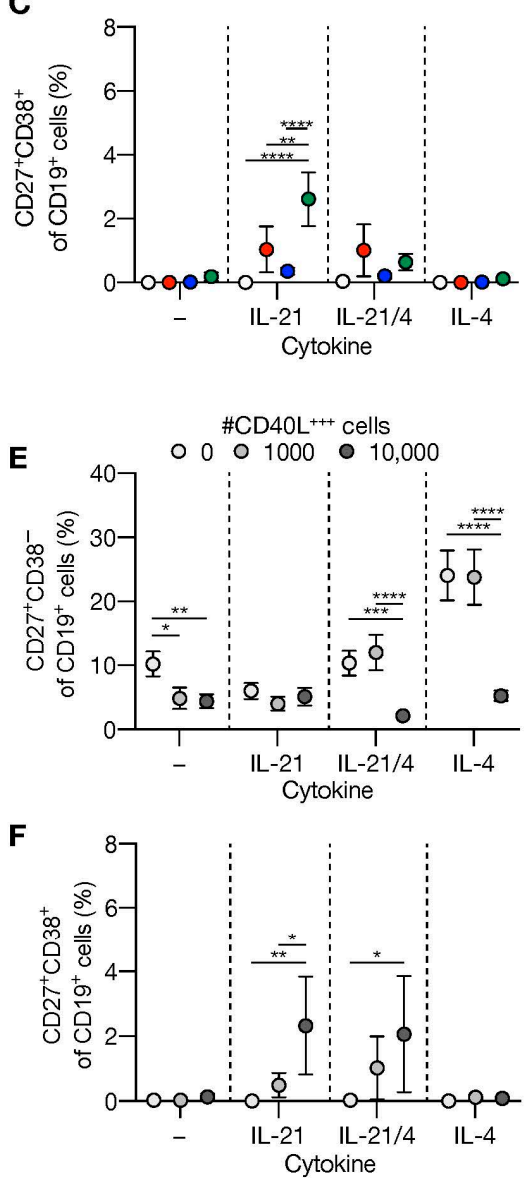

Figure 2. Level of CD40L expression and number of CD40L feeder cells regulates differentiation of human naive B-cell into $\mathrm{CD} 27^{+} \mathrm{CD} 38^{-}$B-cells and $\mathrm{CD} 27^{+} \mathrm{CD} 38^{+}$antibody-secreting cells. (A) Representative of FACS plot showing CD27 and CD38 expression among human naive B-cells cultured on CD40L-expressing 3T3 cells (as in Figure 1A) with or without IL-21 and/or IL-4 for 11 days. $(\mathbf{B}, \mathbf{C})$ The frequency of $\mathrm{CD} 27^{+} \mathrm{CD} 38^{-}(\mathbf{B})$ and $\mathrm{CD} 27^{+} \mathrm{CD} 38^{+}(\mathbf{C})$ populations were analyzed 11 days after culture on CD40L-expressing 3T3 cells and cytokines. (D) Representative plots of human naive B-cells cultured on 0/1000/10,000 CD40L $\mathrm{L}^{+++}$-expressing 3T3 cells (as in Figure 1A) supplemented to 10,000 with WT with or without IL-21 and/or IL-4 for 11 days. (E,F) The frequency of $\mathrm{CD} 27^{+} \mathrm{CD} 38^{-}(\mathrm{E})$ and $\mathrm{CD} 27^{+} \mathrm{CD} 38^{+}(\mathrm{F})$ cells 11 days after culture on

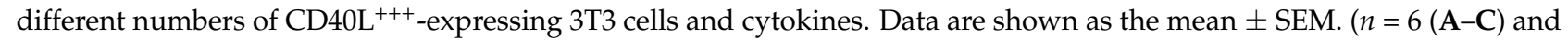
$n=7$ (D-F) independent experiments). Single experiments were conducted in triplicate. Data were analyzed by a two-way ANOVA followed by Tukey's multiple comparison test. ${ }^{*} P \leq 0.05,{ }^{* *} P \leq 0.01,{ }^{* * *} P \leq 0.001,{ }^{* * * *} P \leq 0.0001$. 
A

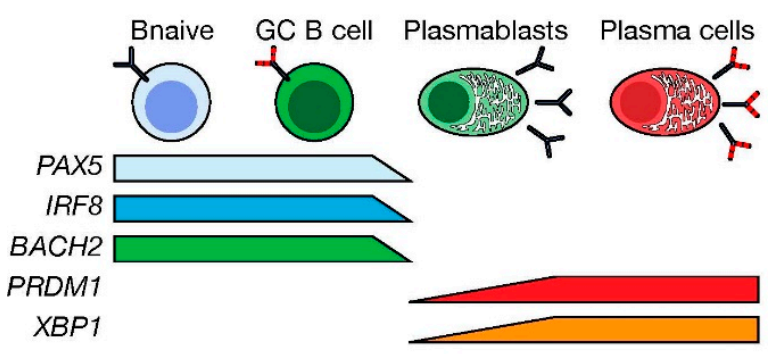

C

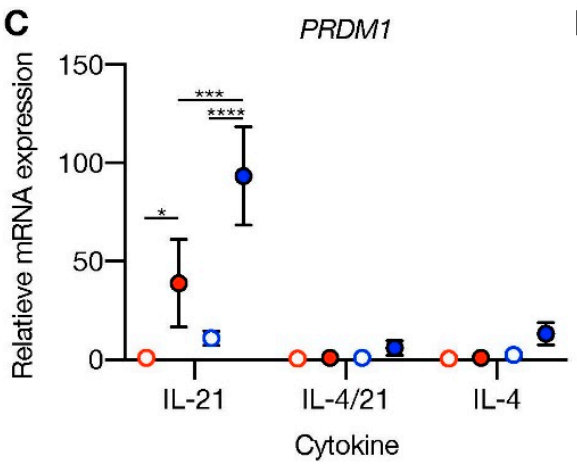

$\mathbf{E}$

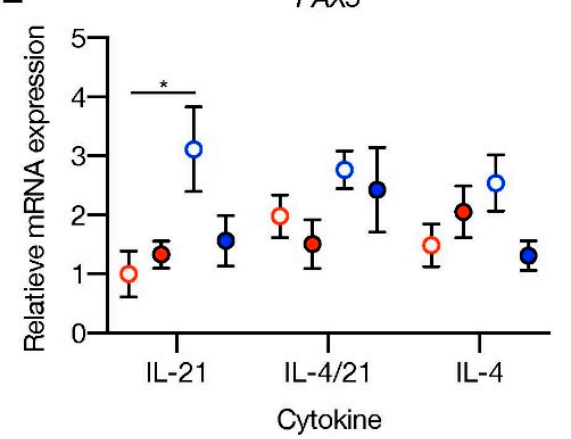

D

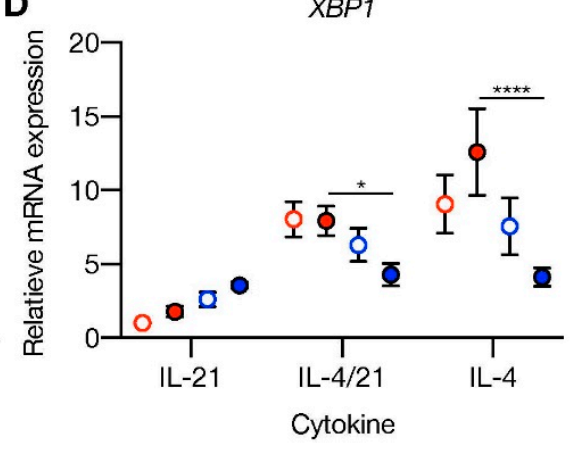

F

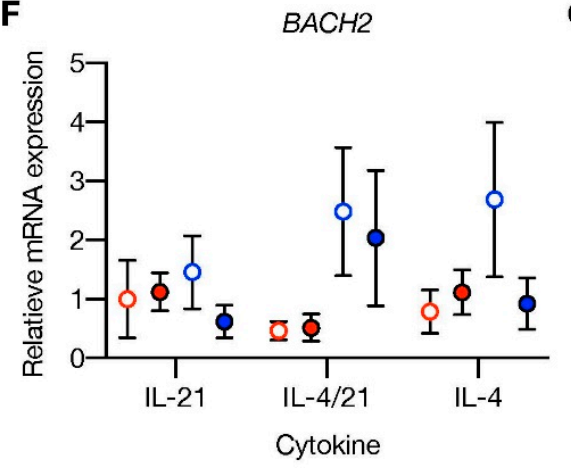

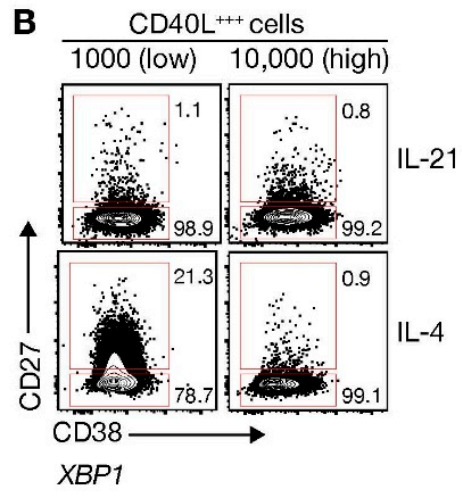

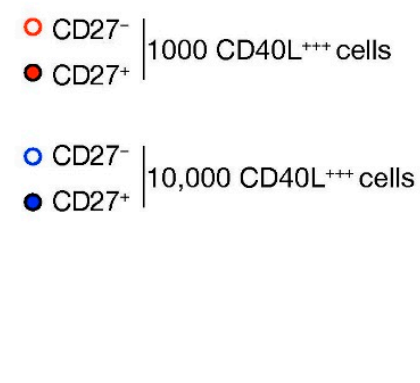

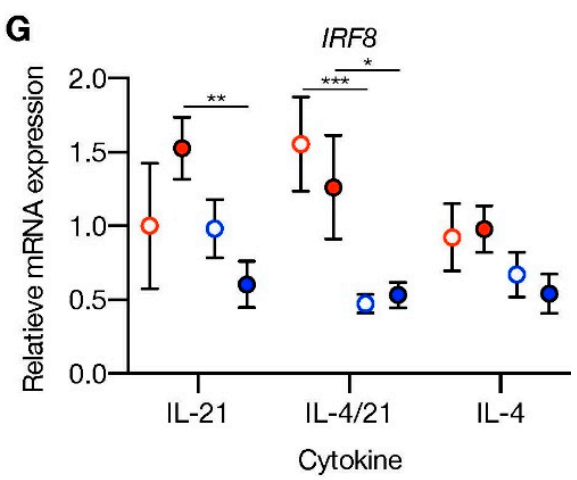

Figure 3. CD40 costimulation together with IL-21 signaling induces PRDM1 expression and does not extinguish the B-cell lineage transcriptional program. (A) Schematic overview of the cellular stages and important transcription factors involved in B-cells differentiation from naive to antibody-secreting plasma cell (GC = germinal center). (B) Representative plots of human naive B-cells cultured on 1000 (low; supplemented with 9000 WT 3T3 cells) or 10,000 (high) CD40L $\mathrm{L}^{+++}$-expressing $3 \mathrm{~T} 3$ cells (as in Figure 1A) with or without IL-21 and/or IL-4 for 9 days. Subsequently, CD27 ${ }^{-} \mathrm{CD} 38^{-}\left(\mathrm{CD} 27^{-}\right)$and $\mathrm{CD} 27^{+} \mathrm{CD} 38^{-}\left(\mathrm{CD} 27^{+}\right)$cells were purified by cell sorting. (C-G) Expression of PRMD1 (C), XBP1 (D), PAX5 (E), BACH2 (F) and IRF8 (G) mRNA in the sorted populations were analyzed by qPCR and related to levels present in the $\mathrm{CD}^{2} 7^{-}$cells that were cultured on 1000 (low) CD40L $\mathrm{L}^{+++}$-expressing 3T3 cells together with IL-21. Data are shown as mean \pm SEM. ( $n=5$ independent experiments). Single experiments were conducted in triplicate. Data were analyzed by a two-way ANOVA followed by Tukey's multiple comparison test. ${ }^{*} P \leq 0.05,{ }^{* *} P \leq 0.01,{ }^{* * *} P \leq 0.001,{ }^{* * * *} P \leq 0.0001$. 
A

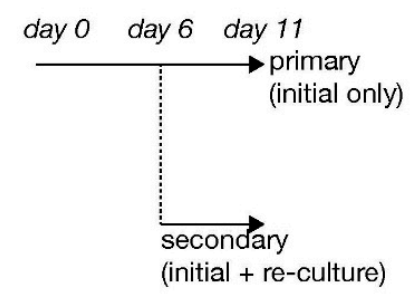

B
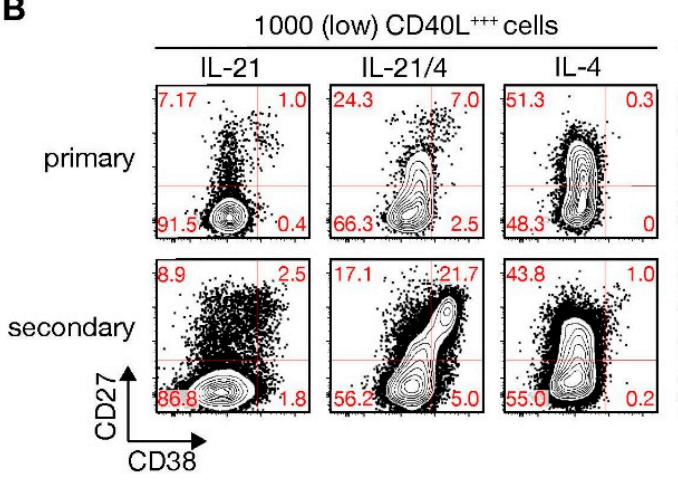

10,000 (high) $\mathrm{CD} 4 \mathrm{LL}^{+++}$cells
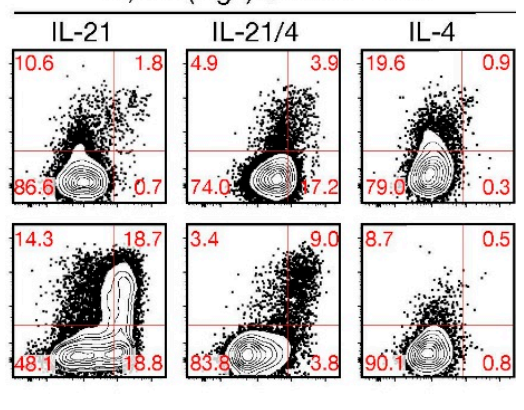

C

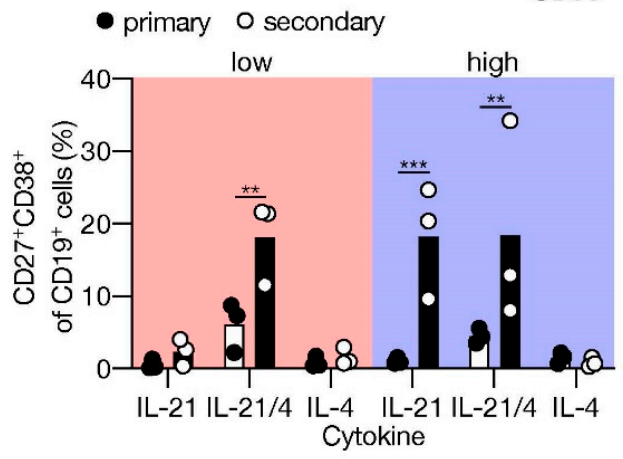

E

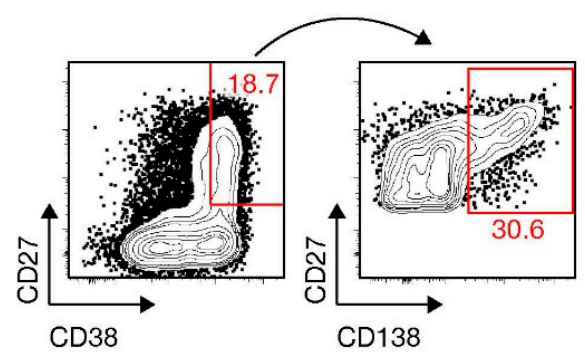

G

- primary (11 days cumulative)

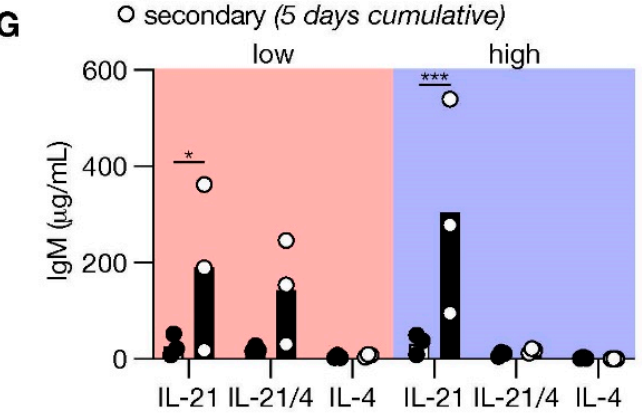

D

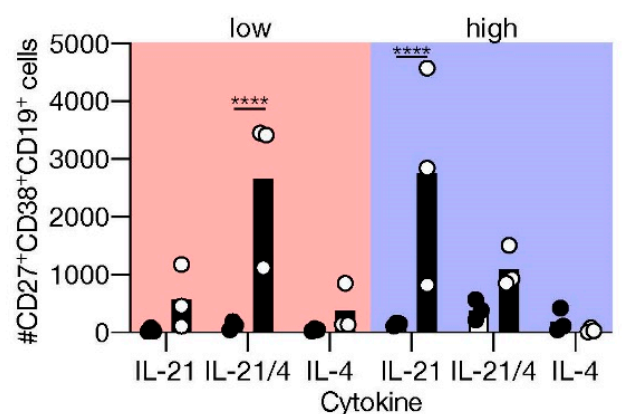

$\mathbf{F}$

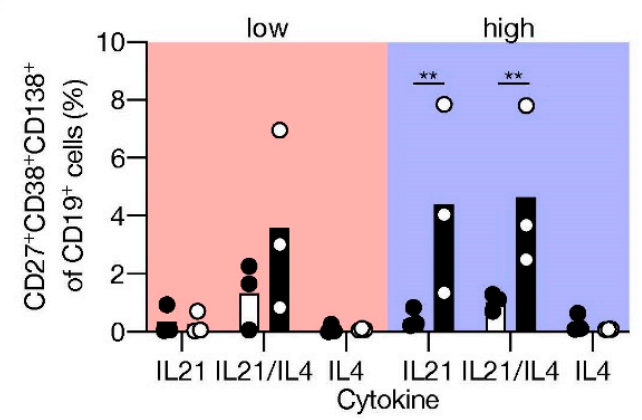

H

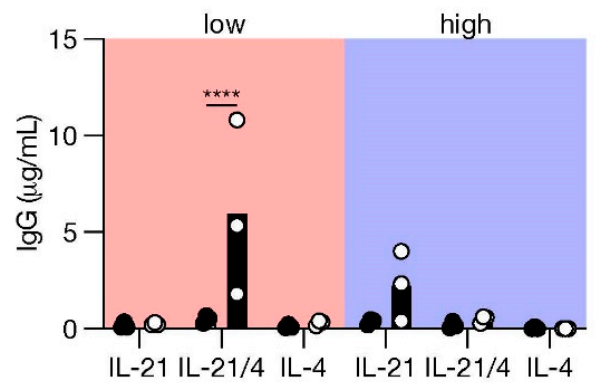

Figure 4. Renewed CD40 costimulation and Tfh cytokines induce in vitro differentiation of human naive B-cells into antibody-secreting cells (ASCs). (A) Human B-cells cultured on 1000 (low; supplemented with 9000 WT 3T3 cells) or 10,000 (high) CD40L $\mathrm{L}^{+++}$-expressing 3T3 cells (as in Figure 1A) with or without IL-21 and/or IL-4 for 11 days (primary-initial only stimulation). Alternatively, primary cultures were harvested after 6 days, and secondary cultures were initiated for 5 days

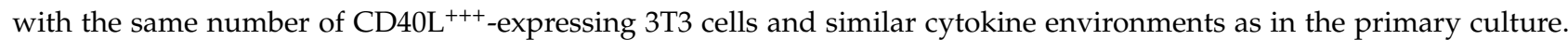
(B) Representative of FACS plots showing CD27 and CD38 expression among human B-cells cultured as in A. (C,D) The frequency (C) and number (D) of $\mathrm{CD} 27^{+} \mathrm{CD} 38^{+}$cells were analyzed 11 days after initial only, or initial + secondary culture. (E) Representative plots of CD138 expression within the $\mathrm{CD} 27^{+} \mathrm{CD} 28^{+}$ASC population. (F) The frequencies of CD138 ${ }^{+}$ plasma cells were determined 11 days after initial only or initial + secondary culture. $(\mathbf{G}, \mathbf{H})$ Cumulative secretion of $\operatorname{IgM}$ (G) and IgG (H) measured in culture supernatants 11 days after initial only or 5 days after initial + secondary culture. Each data point represents the mean of an individual experiment $(n=3)$ with triplicate measurements. Mean values are represented as bars. $p$-values were calculated using multiple t-tests. ${ }^{*} P \leq 0.05,{ }^{* *} P \leq 0.01,{ }^{* * *} P \leq 0.001,{ }^{* * * *} P \leq 0.0001$. 


\subsection{Second Round of In Vitro Stimulation Switches off the B Cell Lineage Program and Induces Rapid Re-Induction of pSTAT3}

ASC differentiation is controlled by a complex interplay of multiple interconnecting transcription factors (Figure 5A). In short, differentiation involves induction of gene expression of the ASC regulator $P R D M 1$, which subsequently represses various important pathways that define the B-cell lineage (PAX5, BACH2 and IRF8). Further characterization of the effects of renewed costimulation and Tfh-cytokine cultures revealed that mRNA levels of ASC-defining transcription factors PRDM1 were not further increased in the FACS-sorted differentiated cells (CD27 ${ }^{-} \mathrm{CD} 38^{+}$and $\mathrm{CD} 27^{+} \mathrm{CD} 38^{+}$ASCs; Figure $\left.5 \mathrm{~B}\right)$ than the $\mathrm{CD} 27^{-} \mathrm{CD} 38^{-} \mathrm{B}$-cells (Figure $5 \mathrm{~B}$ ) after five days into the secondary culture (Figure $5 \mathrm{C}$ ). In contrast, mRNA levels of XBP1 were significantly higher in $\mathrm{CD} 27^{+} \mathrm{CD} 38^{+} \mathrm{ASC}$ s than in the other populations (Figure 5D). Additionally, compared to naive CD27 ${ }^{-} \mathrm{CD} 38^{-}$cells derived from primary cultures, $P R D M 1 \mathrm{mRNA}$ levels were significantly increased, whereas no increase is observed for XBP1 (Figure S8). Interestingly, the mRNA levels of B-celldefining transcription factors PAX5, BACH2 and IRF 8 were significantly decreased in both differentiating populations with the lowest expression in $\mathrm{CD} 27^{+} \mathrm{CD} 38^{+}$ASCs and already profoundly reduced in the undifferentiated cells from secondary cultures than initial culture only (Figure 5E-G and Figure S8). These data demonstrate that re-culture with CD40 costimulation and IL-21 yields full extinguishment of the B-cell transcriptional program and induction of full ASC differentiation of naive B-cells.

A

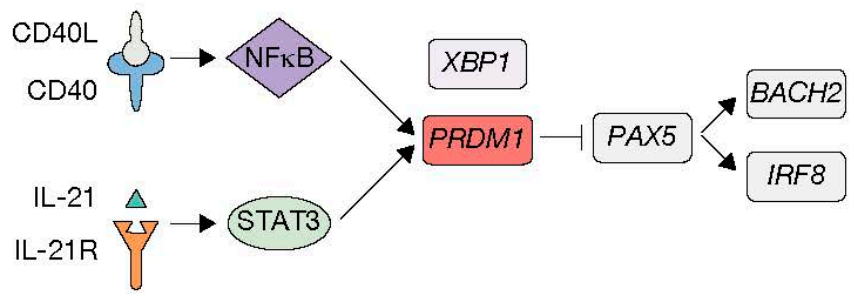

OCD27-CD38- OCD27-CD38+ OCD27+CD38+
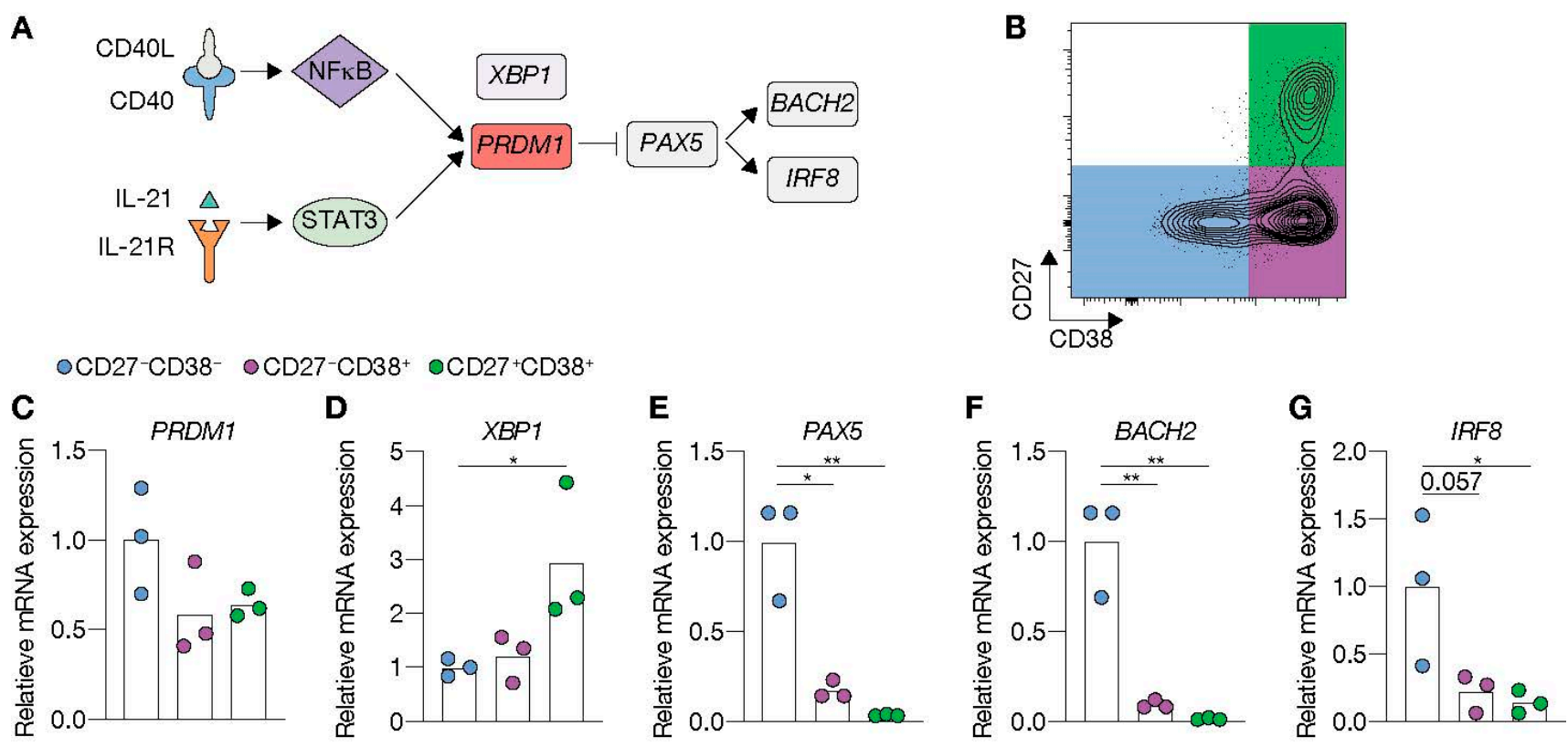

Figure 5. Renewed CD40 costimulation and IL-21 signaling drives antibody-secreting cell (ASC) differentiation and represses transcriptional program related to the B-cell fate. (A) Schematic representation of BLIMP1 activation upon CD40 and IL-21 receptor (IL-21R) signaling. STAT3, together with NFKB, regulates BLIMP1 expression. BLIMP1 downregulates PAX5 expression and, consequently, its downstream targets BACH2 and IRF8. (B-G) Human naive B-cells were cultured

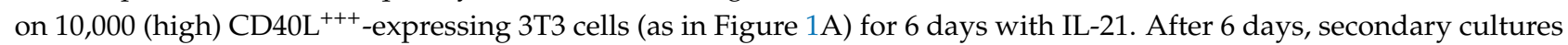
were initiated for 5 days with the initial stimuli. (B) Subsequently, CD27 ${ }^{-} \mathrm{CD} 38^{-}, \mathrm{CD}_{2} 7^{-} \mathrm{CD} 38^{+}$and $\mathrm{CD} 27^{+} \mathrm{CD} 38^{+}$cell populations were sort purified. (C-G) Expression of PRMD1 (C), XBP1 (D), PAX5 (E), BACH2 (F) and IRF8 (G) mRNA in sorted populations were analyzed by $\mathrm{qPCR}$ and related to levels present in $\mathrm{CD}^{-} 7^{-} \mathrm{CD} 38^{-}$cells. Each data point represents the mean of an individual experiment $(n=3)$ with triplicate measurements. Mean values are represented as bars. $p$ values were calculated using RM one-way ANOVA followed by Tukey's multiple comparison test. ${ }^{*} P \leq 0.05$, ${ }^{* *} P \leq 0.01$.

To address further the link between the extracellular signals provided and the induction of a transcriptional program that efficiently induces ASC differentiation, we investigated the kinetics of phosphorylation of STAT3 (pSTAT3; Figure 6A), the signaling molecule positively regulating PRDM1 expression and consequently negatively regulating the B-cell 
transcriptional program (Figure 5A). In line with previous data [33], the presence of IL-21 induced a strong expression of pSTAT3. At the start of culture, pSTAT3 levels in the presence of IL-21 steadily increased and reached maximum levels after 3 days, before return to baseline 3 days later (Figure 6B,C). IL-21 signaling in renewed costimulation cultures induced rapid re-phosphorylation of STAT3 and remained high for at least 3 days (Figure 6D,E). $\mathrm{CD} 27^{+} \mathrm{CD} 38^{+}$cells were observed in the secondary cultures in the presence of IL-21 starting from 3 days and rose to around $15 \%$ after 5 days (Figure S9). These data demonstrate that re-stimulation cultures with CD40L/IL-21 result in rapid re-phosphorylation of STAT3 correlated with efficient naive B-cell differentiation into ASC formation.

A
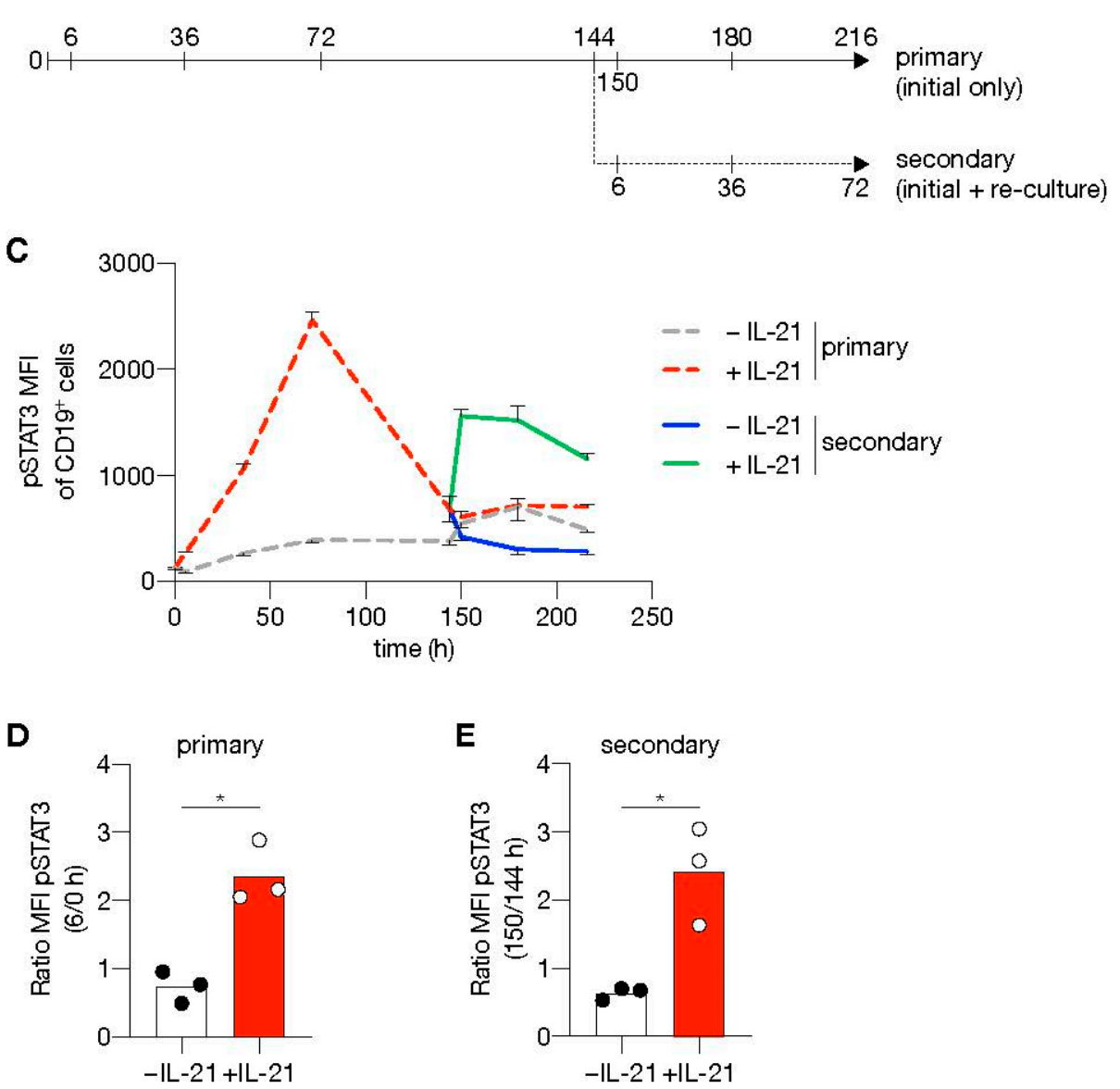

time (h) itial + re-culture)
B

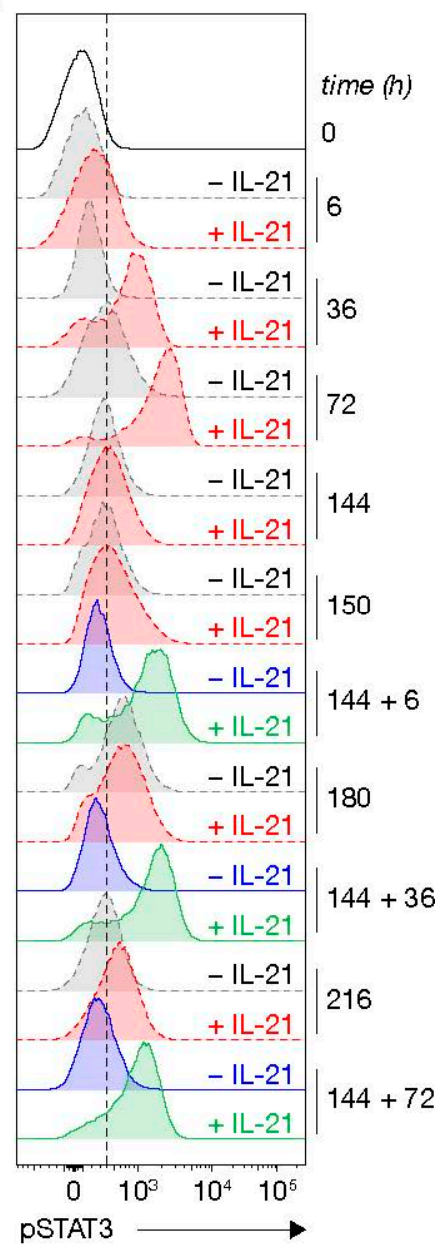

Figure 6. STAT3 is rapidly re-phosphorylated upon re-stimulation using CD40 costimulation and IL-21 signaling. (A) Overview of the time points sampled from primary and secondary human B-cell cultures. Human naive B-cells were cultured on 10,000 CD40L $\mathrm{L}^{+++}$-expressing 3T3 cells (as in Figure 1A) with or without IL-21 for 6 days. After 6 days, secondary cultures were initiated for 3 days with 10,000 CD40L $\mathrm{L}^{+++}$-expressing $3 \mathrm{~T} 3$ cells with(out) IL-21 $(n=3)$. (B,C) Representative plot of pSTAT3 levels (B) and quantification (C) at baseline and 6, 36, 72, 144, 150, 180 and $216 \mathrm{~h}$ in primary culture (dotted gray w/o IL-21 and red lines with IL-21); and 6, 36 and 72 in secondary culture (solid blue w/o IL-21 and green lines with IL-21). Data are shown as mean $\pm \operatorname{SEM}(n=3$ independent experiments). Single experiments were conducted in triplicate. (D, E) Fold induction of pSTAT3 $6 \mathrm{~h}$ in primary (D) and secondary (E) cultures relative to time point 0 or $144 \mathrm{~h}$. Each data point represents the mean of an individual experiment $(n=3)$ with triplicate measurements. Mean values are represented as bars. $p$ values were calculated using paired t-test. ${ }^{*} P \leq 0.05$.

\section{Discussion}

In this study, we established an in vitro culture system that could efficiently differentiate human peripheral blood naive B-cells into ASCs. We demonstrate that naive B-cell 
survival, abundance and differentiation are dependent on CD40L expression levels by the feeder cells used in the in vitro culture system and on the cytokine environment provided. We also show that renewed costimulation greatly enhanced ASC differentiation. Low CD40 costimulation in the presence of IL-4 prominently induces $\mathrm{CD} 27^{+} \mathrm{CD} 38^{-}$cells, compared to high costimulation. CD27 is used as a discriminate marker for human MBCs in blood, raising the possibility that our observed $\mathrm{CD} 27^{+} \mathrm{CD} 38^{-}$cells represent the development of the MBCs. However, current discussions in the field attribute the appearance of CD27 to the status of activation, especially in vitro, and not necessarily the formation of long-lived MBCs (reviewed in [34]). Therefore, we cannot make any firm conclusions on MBC formation in our system. Survival of human B-cells under high CD40 costimulatory conditions in vitro was superior in the presence of IL-21. Additionally, these stimulatory conditions made human naive B-cells more prone to differentiate into $\mathrm{CD} 27^{+} \mathrm{CD} 38^{+} \mathrm{ASC}$ even though the magnitude of ASC formation was low. Although PRDM1 was upregulated in the culture, the B-cell lineage program was unaltered, possibly contributing to the low magnitude of ASC formation in vitro. However, similar observations have been made in mice in a subset of proliferating dark zone GC B-cells that have low expression of BLIMP1 [35]. These GC B-cells were also not fully committed to PC differentiation but may be more prone to differentiation via that route.

During GC reactions in vivo, GC B-cells repeatedly interact over several cycles, with Tfh cells that provide, among others, CD40 costimulation, IL-21 and IL-4 to the interacting B-cells. Therefore, to mimic the in vivo GC reactions, we utilized secondary cultures, including CD40 costimulation and cytokine stimulation succeeding initial stimulation. Renewed CD40 costimulation in the presence of IL-21 prominently induced ASC formation and concomitantly decreased expression of B-cell-defining transcription factors PAX5, $B A C H 2$ and IRF8. This demonstrates that also in vitro human naive B-cells, after initial proliferation, require renewed Tfh cell signals to transcend a minimal signaling threshold required for effective differentiation into ASCs. We did observe discrepancies between the expression levels of PRDM1 and XBP1, two transcription factors important in ASC differentiation and function. In secondary cultures, $P R D M 1$ levels were already increased in the undifferentiated $\mathrm{CD} 27^{-} \mathrm{CD} 38^{-}$population and remained constant in the differentiated populations, whereas XBP1 levels only increased in the fully differentiated $\mathrm{CD} 27^{+} \mathrm{CD} 38^{+}$ ASC. This indicates that PRDM1 is important before the fate transition to really drive differentiation, whereas XBP1 is relevant for the large production of antibodies.

Previous studies using murine naive B-cells reported that CD40L stimulation, with or without BAFF stimulation, together with phasic (re-)stimulation of IL-21 and IL-4, resulted in significant expansion and induction of GC-like cells and differentiation into CD138 ${ }^{+}$cells. These cells required an adoptive transfer model to fully mature into long-lived PCs [36,37]. We here show that for human in vitro naive B-cell differentiation, renewed costimulation and Tfh-cytokines during the B-cell priming phase induce potent plasmablast (PB) and PCs formation from CD40L-stimulated naive B-cells in the presence of IL-21 - /+ IL-4. Whether these are long-lived PCs as observed in the adoptive transfer model [37] remains to be determined. Other groups have demonstrated in vitro differentiation of human MBCs into long-lived PCs using an intricate 3-step culture system, in which stromal cell factors, mimicking the bone marrow environment, prolonged the survival of the in vitro-generated PCs $[38,39]$. This could be the next step in our human naive B-cell culture system to assess the longevity of our induced ASCs.

Renewed CD40 costimulation of human naive B-cells in vitro with high CD40L levels in the presence of IL-21 rapidly re-induced STAT3 activation, an IL-21 receptor signaling protein. Individuals with STAT3 mutations and mice deficient for IL-21 or IL-21 receptor have shown that STAT3 is essential in GC formation and maintenance, PC differentiation and immunoglobulin secretion [18,19,40-42]. Furthermore, IL-21 synergizes with CD40L stimulation to induce expression of the ASC-defining transcription factors PRDM1 and IRF4 in human B-cells [43]. Altogether, the observed rapid re-induction of STAT3 in the 
secondary in vitro cultures could explain the more prominent ASC induction and suggests that dynamic reexpression of STAT3 is important in ASC differentiation.

The establishment of this minimalistic in vitro culture system that supports efficient differentiation of human naive B-cells into antibody-secreting cells while also maintaining high cell numbers to investigate the differentiation pathways may form an important step for the much-desired in-depth dissection of human B-cell terminal differentiation. It may eventually prove beneficial in devising new strategies and targets for treating antibody/ASC-mediated inflammatory and auto-immune diseases and might prove invaluable for monitoring vaccination efficiency.

Supplementary Materials: The following are available online at https://www.mdpi.com/article/ 10.3390/cells10051183/s1, Figure S1: Level of CD40L expression affects the expansion of six-day stimulated naive B-cells, Figure S2: BCR ligation does not affect human naive B-cell differentiation upon CD40 costimulation, Figure S3: Secreted antibodies do not recognize 3T3 cells, Figure S4: Moderate correlation between the frequency of IgG cells and IgG secretion, Figure S5: Naive B-cells compete for CD40L-expressing cells, Figure S6: The number of CD40L-expressing cells affects naive B-cells expansion and AICDA expression, Figure S7: Re-stimulation via CD40 and Tfh cytokine signaling minimally affects the number of live CD19+ cells, Figure S8: B-cells are transcriptionally prepared before transition into the antibody-secreting cell fate, Figure S9: Re-stimulation via CD40 and IL-21 signaling efficiently promotes B-cell fate transition into CD27+CD38+ antibody-secreting cells. Table S1: Primer sequences.

Author Contributions: P.-P.A.U., N.J.M.V., A.t.B., and S.M.v.H. conceived the ideas and designed the experiments. P.-P.A.U., N.J.M.V., C.M., T.J., performed the experiments. P.-P.A.U., N.J.M.V., C.M., T.J., T.R., A.t.B. and S.M.v.H. analyzed the data. N.J.M.V., P.-P.A.U., A.t.B. and S.M.v.H. wrote the manuscript. All authors have read and agreed to the published version of the manuscript.

Funding: This research was made possible thanks to the financial support of the Landsteiner Foundation for Blood Transfusion Research, grant 1609 to S.M. van Ham (for C. Marsman), Sanquin Innovation Grant 2020-45 to S.M. van Ham (for T. Jorritsma) and Sanquin Product/process-development project PPOC-17-34 to S.M. van Ham (for P.-P. Unger).

Institutional Review Board Statement: The study was conducted following the protocol of the local institutional review board, the Medical Ethics Committee of Sanquin Blood Supply, and conforms to the principles of the Declaration of Helsinki.

Informed Consent Statement: Informed consent was obtained from all subjects involved in the study.

Data Availability Statement: The data presented in this study are available on request from the corresponding author.

Acknowledgments: We thank Erik Mul, Simon Tol, Floris van Alphen and Mark Hoogenboezem for sorting naive B-cells using flow cytometry. We thank Gordon J. Freeman of the DFCI, Harvard, for kindly providing us with the human CD40L plasmid $[27,28]$.

Conflicts of Interest: The authors declare no conflict of interest. The funders had no role in the design of the study; in the collection, analyses or interpretation of data; in the writing of the manuscript; or in the decision to publish the results.

\section{References}

1. Zimring, J.C.; Stowell, S.R.; Johnsen, J.M.; Hendrickson, J.E. Effects of genetic, epigenetic, and environmental factors on alloimmunization to transfused antigens: Current paradigms and future considerations. Transfus. Clin. Biol. 2012, 19, 125-131. [CrossRef]

2. Zimring, J.C.; Hudson, K.E. Cellular immune responses in red blood cell alloimmunization. Hematology 2016, $2016,452-456$. [CrossRef] [PubMed]

3. Laffitte, E.; Skaria, M.; Jaunin, F.; Tamm, K.; Saurat, J.-H.; Favre, B.; Borradori, L. Autoantibodies to the extracellular and intracellular domain of bullous pemphigoid 180, the putative key autoantigen in bullous pemphigoid, belong predominantly to the IgG1 and IgG4 subclasses. Br. J. Dermatol. 2001, 144, 760-768. [CrossRef] [PubMed]

4. Gilhus, N.E.; Skeie, G.O.; Romi, F.; Lazaridis, K.; Zisimopoulou, P.; Tzartos, S. Myasthenia gravis-Autoantibody characteristics and their implications for therapy. Nat. Rev. Neurol. 2016, 12, 259-268. [CrossRef] 
5. Berentsen, S.; Sundic, T. Red Blood Cell Destruction in Autoimmune Hemolytic Anemia: Role of Complement and Potential New Targets for Therapy. BioMed Res. Int. 2015, 2015, 363278. [CrossRef]

6. Pos, W.; Luken, B.M.; Sorvillo, N.; Kremer Hovinga, J.A.; Voorberg, J. Humoral immune response to ADAMTS13 in acquired thrombotic thrombocytopenic purpura. J. Thromb. Haemost. 2011, 9, 1285-1291. [CrossRef] [PubMed]

7. Weinstein, J.S.; Herman, E.I.; Lainez, B.; Licona-Limón, P.; Esplugues, E.; Flavell, R.; Craft, J. TFH cells progressively differentiate to regulate the germinal center response. Nat. Immunol. 2016, 17, 1197-1205. [CrossRef] [PubMed]

8. King, C.; Tangye, S.G.; Mackay, C.R. T Follicular Helper (T FH) Cells in Normal and Dysregulated Immune Responses. Annu. Rev. Immunol. 2008, 26, 741-766. [CrossRef]

9. Zaretsky, A.G.; Taylor, J.J.; King, I.L.; Marshall, F.A.; Mohrs, M.; Pearce, E.J. T follicular helper cells differentiate from Th2 cells in response to helminth antigens. J. Exp. Med. 2009, 206, 991-999. [CrossRef]

10. Bryant, V.L.; Ma, C.S.; Avery, D.T.; Li, Y.; Good, K.L.; Corcoran, L.M.; de Waal Malefyt, R.; Tangye, S.G. Cytokine-mediated regulation of human B cell differentiation into Ig-secreting cells: Predominant role of IL-21 produced by CXCR5+ T follicular helper cells. J. Immunol. 2007, 179, 8180-8190. [CrossRef]

11. Reinhardt, R.L.; Liang, H.-E.; Locksley, R.M. Cytokine-secreting follicular T cells shape the antibody repertoire. Nat. Immunol. 2009, 10, 385-393. [CrossRef]

12. King, I.L.; Mohrs, M. IL-4-producing CD4+ T cells in reactive lymph nodes during helminth infection are T follicular helper cells. J. Exp. Med. 2009, 206, 1001-1007. [CrossRef] [PubMed]

13. Yusuf, I.; Kageyama, R.; Monticelli, L.; Johnston, R.J.; Ditoro, D.; Hansen, K.; Barnett, B.; Crotty, S. Germinal center T follicular helper cell IL-4 production is dependent on signaling lymphocytic activation molecule receptor (CD150). J. Immunol. 2010, 185, 190-202. [CrossRef] [PubMed]

14. Victora, G.D.; Nussenzweig, M.C. Germinal Centers. Annu. Rev. Immunol. 2012, 30, 429-457. [CrossRef] [PubMed]

15. De Silva, N.S.; Klein, U. Dynamics of B cells in germinal centres. Nat. Rev. Immunol. 2015, 15, 137-148. [CrossRef] [PubMed]

16. Takahashi, Y.; Dutta, P.R.; Cerasoli, D.M.; Kelsoe, G. In situ studies of the primary immune response to (4-hydroxy-3nitrophenyl)acetyl. V. Affinity maturation develops in two stages of clonal selection. J. Exp. Med. 1998, 187, 885-895. [CrossRef] [PubMed]

17. Weisel, F.J.; Zuccarino-Catania, G.V.; Chikina, M.; Shlomchik, M.J. A Temporal Switch in the Germinal Center Determines Differential Output of Memory B and Plasma Cells. Immunity 2016, 44, 116-130. [CrossRef]

18. Linterman, M.A.; Beaton, L.; Yu, D.; Ramiscal, R.R.; Srivastava, M.; Hogan, J.J.; Verma, N.K.; Smyth, M.J.; Rigby, R.J.; Vinuesa, C.G. IL-21 acts directly on B cells to regulate Bcl-6 expression and germinal center responses. J. Exp. Med. 2010, 207, 353-363. [CrossRef]

19. Zotos, D.; Coquet, J.M.; Zhang, Y.; Light, A.; D’Costa, K.; Kallies, A.; Corcoran, L.M.; Godfrey, D.I.; Toellner, K.-M.; Smyth, M.J.; et al. IL-21 regulates germinal center B cell differentiation and proliferation through a B cell-intrinsic mechanism. J. Exp. Med. 2010, 207, 365-378. [CrossRef]

20. Mak, T.W.; Shahinian, A.; Yoshinaga, S.K.; Wakeham, A.; Boucher, L.-M.; Pintilie, M.; Duncan, G.; Gajewska, B.U.; Gronski, M.; Eriksson, U.; et al. Costimulation through the inducible costimulator ligand is essential for both $\mathrm{T}$ helper and $\mathrm{B}$ cell functions in $\mathrm{T}$ cell-dependent B cell responses. Nat. Immunol. 2003, 4, 765-772. [CrossRef]

21. Gatto, D.; Pfister, T.; Jegerlehner, A.; Martin, S.W.; Kopf, M.; Bachmann, M.F. Complement receptors regulate differentiation of bone marrow plasma cell precursors expressing transcription factors Blimp-1 and XBP-1. J. Exp. Med. 2005, 201, 993-1005. [CrossRef]

22. Good-Jacobson, K.L.; Szumilas, C.G.; Chen, L.; Sharpe, A.H.; Tomayko, M.M.; Shlomchik, M.J. PD-1 regulates germinal center B cell survival and the formation and affinity of long-lived plasma cells. Nat. Immunol. 2010, 11, 535-542. [CrossRef]

23. Good-Jacobson, K.L.; Song, E.; Anderson, S.; Sharpe, A.H.; Shlomchik, M.J. CD80 expression on B cells regulates murine T follicular helper development, germinal center B cell survival, and plasma cell generation. J. Immunol. 2012, 188, 4217-4225. [CrossRef] [PubMed]

24. Deenick, E.K.; Avery, D.T.; Chan, A.; Berglund, L.J.; Ives, M.L.; Moens, L.; Stoddard, J.L.; Bustamante, J.; Boisson-Dupuis, S.; Tsumura, M.; et al. Naive and memory human B cells have distinct requirements for STAT3 activation to differentiate into antibody-secreting plasma cells. J. Exp. Med. 2013, 210, 2739-2753. [CrossRef] [PubMed]

25. Ise, W.; Fujii, K.; Shiroguchi, K.; Ito, A.; Kometani, K.; Takeda, K.; Kawakami, E.; Yamashita, K.; Suzuki, K.; Okada, T.; et al. T Follicular Helper Cell-Germinal Center B Cell Interaction Strength Regulates Entry into Plasma Cell or Recycling Germinal Center Cell Fate. Immunity 2018, 48, 702-715. [CrossRef]

26. Néron, S.; Racine, C.; Roy, A.; Guérin, M. Differential responses of human B-lymphocyte subpopulations to graded levels of CD40-CD154 interaction. Immunology 2005, 116, 454-463. [CrossRef] [PubMed]

27. Urashima, M.; Chauhan, D.; Uchiyama, H.; Freeman, G.; Anderson, K. CD40 ligand triggered interleukin-6 secretion in multiple myeloma. Blood 1995, 85, 1903-1912. [CrossRef]

28. Schultze, J.L.; Cardoso, A.A.; Freeman, G.J.; Seamon, M.J.; Daley, J.; Pinkus, G.S.; Gribben, J.G.; Nadler, L.M. Follicular lymphomas can be induced to present alloantigen efficiently: A conceptual model to improve their tumor immunogenicity. Proc. Natl. Acad. Sci. USA 1995, 92, 8200-8204. [CrossRef] 
29. Verstegen, N.J.M.; Unger, P.-P.A.; Walker, J.Z.; Nicolet, B.P.; Jorritsma, T.; van Rijssel, J.; Spaapen, R.M.; de Wit, J.; van Buul, J.D.; ten Brinke, A.; et al. Human B Cells Engage the NCK/PI3K/RAC1 Axis to Internalize Large Particles via the IgM-BCR. Front. Immunol. 2019, 10, 1-14. [CrossRef]

30. Souwer, Y.; Griekspoor, A.; Jorritsma, T.; de Wit, J.; Janssen, H.; Neefjes, J.; van Ham, S.M. B cell receptor-mediated internalization of salmonella: A novel pathway for autonomous B cell activation and antibody production. J. Immunol. 2009, 182, 7473-7481. [CrossRef]

31. Avery, D.T.; Bryant, V.L.; Ma, C.S.; de Waal Malefyt, R.; Tangye, S.G. IL-21-induced isotype switching to IgG and IgA by human naive B cells is differentially regulated by IL-4. J. Immunol. 2008, 181, 1767-1779. [CrossRef]

32. Muramatsu, M.; Kinoshita, K.; Fagarasan, S.; Yamada, S.; Shinkai, Y.; Honjo, T. Class Switch Recombination and Hypermutation Require Activation-Induced Cytidine Deaminase (AID), a Potential RNA Editing Enzyme. Cell 2000, 102, 553-563. [CrossRef]

33. Marsman, C.; Jorritsma, T.; ten Brinke, A.; van Ham, S.M. Flow Cytometric Methods for the Detection of Intracellular Signaling Proteins and Transcription Factors Reveal Heterogeneity in Differentiating Human B Cell Subsets. Cells 2020, 9, 2633. [CrossRef] [PubMed]

34. Weisel, F.; Shlomchik, M. Memory B Cells of Mice and Humans. Annu. Rev. Immunol. 2017, 35, 255-284. [CrossRef] [PubMed]

35. Radtke, D.; Bannard, O. Expression of the Plasma Cell Transcriptional Regulator Blimp-1 by Dark Zone Germinal Center B Cells During Periods of Proliferation. Front. Immunol. 2019, 9, 1-16. [CrossRef] [PubMed]

36. Robinson, M.J.; Pitt, C.; Brodie, E.J.; Valk, A.M.; O’Donnell, K.; Nitschke, L.; Jones, S.; Tarlinton, D.M. BAFF, IL-4 and IL-21 separably program germinal center-like phenotype acquisition, BCL6 expression, proliferation and survival of CD40L-activated B cells in vitro. Immunol. Cell Biol. 2019, 97, 826-839. [CrossRef] [PubMed]

37. Nojima, T.; Haniuda, K.; Moutai, T.; Matsudaira, M.; Mizokawa, S.; Shiratori, I.; Azuma, T.; Kitamura, D. In-vitro derived germinal centre B cells differentially generate memory B or plasma cells in vivo. Nat. Commun. 2011, 2, 465. [CrossRef]

38. Cocco, M.; Stephenson, S.; Care, M.A.; Newton, D.; Barnes, N.A.; Davison, A.; Rawstron, A.; Westhead, D.R.; Doody, G.M.; Tooze, R.M. In vitro generation of long-lived human plasma cells. J. Immunol. 2012, 189, 5773-5785. [CrossRef]

39. Jourdan, M.; Caraux, A.; De Vos, J.; Fiol, G.; Larroque, M.; Cognot, C.; Bret, C.; Duperray, C.; Hose, D.; Klein, B. An in vitro model of differentiation of memory B cells into plasmablasts and plasma cells including detailed phenotypic and molecular characterization. Blood 2009, 114, 5173-5181. [CrossRef]

40. Avery, D.T.; Deenick, E.K.; Ma, C.S.; Suryani, S.; Simpson, N.; Chew, G.Y.; Chan, T.D.; Palendira, U.; Bustamante, J.; BoissonDupuis, S.; et al. B cell-intrinsic signaling through IL-21 receptor and STAT3 is required for establishing long-lived antibody responses in humans. J. Exp. Med. 2010, 207, 155-171. [CrossRef]

41. McGuire, H.M.; Vogelzang, A.; Warren, J.; Loetsch, C.; Natividad, K.D.; Chan, T.D.; Brink, R.; Batten, M.; King, C. IL-21 and IL-4 Collaborate to Shape T-Dependent Antibody Responses. J. Immunol. 2015, 195, 5123-5135. [CrossRef] [PubMed]

42. Veen, W.; Krätz, C.E.; McKenzie, C.I.; Aui, P.M.; Neumann, J.; Noesel, C.J.M.; Wirz, O.F.; Hagl, B.; Kröner, C.; Spielberger, B.D.; et al. Impaired memory B-cell development and antibody maturation with a skewing toward IgE in patients with STAT3 hyper-IgE syndrome. Allergy 2019, 74, 2394-2405. [CrossRef] [PubMed]

43. Ding, B.B.; Bi, E.; Chen, H.; Yu, J.J.; Ye, B.H. IL-21 and CD40L synergistically promote plasma cell differentiation through upregulation of Blimp-1 in human B cells. J. Immunol. 2013, 190, 1827-1836. [CrossRef] [PubMed] 